\title{
Modelling soil temperature and moisture and corresponding seasonality of photosynthesis and transpiration in a boreal spruce ecosystem
}

\author{
S. H. Wu ${ }^{1, *}$ and P.-E. Jansson ${ }^{1}$ \\ ${ }^{1}$ Department of Land and Water Resources Engineering, Royal Institute of Technology (KTH), Brinellvägen 28, \\ 10044 Stockholm, Sweden \\ " now at: National Centre for Science and Technology Evaluation, 100081 Bejing, China
}

Correspondence to: $\mathrm{S} . \mathrm{H} . \mathrm{Wu}$ (sihong @ kth.se)

Received: 16 April 2012 - Published in Hydrol. Earth Syst. Sci. Discuss.: 24 May 2012

Revised: 18 December 2012 - Accepted: 27 January 2013 - Published: 20 February 2013

\begin{abstract}
Recovery of photosynthesis and transpiration is strongly restricted by low temperatures in air and/or soil during the transition period from winter to spring in boreal zones. The extent to which air temperature $\left(T_{\mathrm{a}}\right)$ and soil temperature $\left(T_{\mathrm{S}}\right)$ influence the seasonality of photosynthesis and transpiration of a boreal spruce ecosystem was investigated using a process-based ecosystem model (CoupModel) together with eddy covariance (EC) data from one eddy flux tower and nearby soil measurements at Knottåsen, Sweden. A Monte Carlo-based uncertainty method (GLUE) provided prior and posterior distributions of simulations representing a wide range of soil conditions and performance indicators. The simulated results showed sufficient flexibility to predict the measured cold and warm $T_{\mathrm{S}}$ in the moist and dry plots around the eddy flux tower. Moreover, the model presented a general ability to describe both biotic and abiotic processes for the Norway spruce stand. The dynamics of sensible heat fluxes were well described by the corresponding latent heat fluxes and net ecosystem exchange of $\mathrm{CO}_{2}$. The parameter ranges obtained are probably valid to represent regional characteristics of boreal conifer forests, but were not easy to constrain to a smaller range than that produced by the assumed prior distributions. Finally, neglecting the soil temperature response function resulted in fewer behavioural models and probably more compensatory errors in other response functions for regulating the seasonality of ecosystem fluxes.
\end{abstract}

\section{Introduction}

Forests in boreal areas are likely to be considerably influenced by climate change, elevated $\mathrm{CO}_{2}$ and management (Schröter et al., 2005; Boisvenue and Running, 2006; Jansson et al., 2008). Thus, understanding the interaction between ecosystem processes and historical climate conditions is fundamental to predicting how the ecosystem will be affected by environmental changes. In boreal conifer forests, the climate both aboveground and belowground regulates photosynthesis and transpiration processes (Suni et al., 2003; Mellander et al., 2008). Furthermore, temperature is recognised as a vital environmental factor affecting carbon dynamics and budgets (Bergh and Linder, 1999; Kolari et al., 2007; Lindroth et al., 2008).

Recovery of photosynthesis and transpiration is strongly restricted by low temperatures in air and/or soil during the transition period from winter to spring (Mäkelä et al., 2004; Mellander et al., 2006; Ensiminger et al., 2008; Wu et al., 2011, 2012). Moreover, photosynthesis recovery in spring varies annually, which is probably caused by both atmospheric and soil conditions. Currently, there is no general agreement on the specific roles of air and soil temperature in regulation of photosynthesis processes, especially in spring, according to field experimental data and modelling studies. The atmospheric conditions will sometime create a high requirement for transpiration and photosynthesis when the plant is not fully adapted to high light intensity or high air temperature while the soil is still very cold. 
In a previous site-specific modelling study based on longterm measurements, we sought to distinguish and quantify the specific roles of air and soil temperature in the seasonality of photosynthesis and transpiration for a boreal Scots pine stand at Hyytiälä, Finland (Wu et al., 2012). The conclusion was that air temperature was the major limiting factor for photosynthesis in early spring, autumn and winter, but soil temperature was a rather important limiting factor for photosynthesis in late spring and summer. The results also suggested that inhibition of photosynthesis and transpiration due to low soil temperature needs to be considered in the model when there is a large delay between cumulative air temperature $\left(T_{\mathrm{a}}\right)$ and soil temperature $\left(T_{\mathrm{s}}\right)$ in spring.

In the present study we sought to test the general validity of the conclusions drawn from the long-term simulations of the Scots pine stand at Hyytiälä (Wu et al., 2012). Another area of interest was to examine photosynthesis and transpiration responses to heterogeneous soil conditions using soil temperature and moisture measurements representing large spatial variability in the field. The Swedish site of Knottåsen has similar boreal climate conditions and measurements to Hyytiälä. Long-terms measurements at Knottåsen have produced a large quantity of eddy covariance data and numerous biomass and soil measurements describing spatial variability within the radius of the eddy-covariance flux tower. Therefore data from the Knottåsen site were deemed suitable for analysing our specific interests in this study.

Previous studies of the spruce forest at Knottåsen in 2001 and 2002 within the LUSTRA programme mainly focused on pools and fluxes of carbon (Berggren et al., 2004; Berggren Kleja et al., 2008; Lindroth et al., 2008). It is interesting to note that the role of soil carbon pools has been interpreted differently using different data sources. For instance, a large carbon loss $\left(210-240 \mathrm{~g} \mathrm{C} \mathrm{m}^{-2} \mathrm{yr}^{-1}\right)$ from soil according to measured "NEE" and tree growth was reported by Lindroth et al. (2008), whereas a small change in soil carbon pools was estimated by Berggren Kleja et al. (2008) using CoupModel. However, the seasonality of carbon, water and heat fluxes at Knottåsen is not fully studied and the responses of these variables to abiotic conditions have not been examined. In the current study, based on the datasets from Knottåsen and the information obtained from modelling studies at Hyytiälä, new simulations were made for Knottåsen to test the applicability of the model in simulating seasonal patterns of photosynthesis and transpiration in response to cold climate.

Specific objectives were to: (1) test the general validity of a model simulating the seasonal patterns of carbon, water and heat fluxes of a Norway spruce stand at Knottåsen, Sweden, based on long-term data from a previous study of a Scots pine stand at Hyytiälä, southern Finland; (2) examine the spatial variability in soil temperature and moisture and the possibility to simulate those conditions; and (3) present simulated results on the impacts of spatial variability in soil temperature and moisture on the regulation of photosynthesis and transpiration.

\section{Materials and methods}

\subsection{Study site description}

Field measurements conducted at Knottåsen, Sweden $\left(61^{\circ} 00^{\prime} \mathrm{N}, 16^{\circ} 13^{\prime} \mathrm{E}\right)$, with detailed descriptions of the site and instrumentation, can be found in Berggren et al. (2004), Berggren Kleja et al. (2008) and Lindroth et al. (2008). This site was clear-cut in 1963 and the current stands were planted in 1965 with two-year-old seedlings of Norway spruce (Picea abies L.), which now dominates this site, with some occurrence of Scots pine (Pinus sylvestris L.). During 1961-1990 average annual air temperature was $3.4^{\circ} \mathrm{C}$, average annual precipitation was $613 \mathrm{~mm}$, and the average growing season length was 160 days (Berggren et al., 2004). Three plots $(30 \mathrm{~m} \times 30 \mathrm{~m})$ in each of three different moisture classes (dry, mesic and moist) were set up in 2000 for the LUSTRA project. The dry and mesic conditions dominate the area but all plots are located in the nearby conditions to the tower. The two closed plots are one moist and two dry. All drainage conditions occur in all directions around the tower. The site is situated on acidic bedrock and the soil is a Haplic Podsol in the dry and mesic plots and a Gley Podsol in the moist plots (Berggren et al., 2004).

\subsection{Data used for this study}

In order to test the applicability of the model, measured datasets for Knottåsen were prepared especially for the current study, including both high and low resolution data similar to that used for Scots pine forest studies at Hyytiälä (Wu et al., 2011). Most data were available for the period 20012003. Hourly mean values of eddy flux data, meteorological variables, soil temperature, soil moisture, snow depth and water table depth was used to calibrate the model. In addition, forest inventory data and soil physical data were used to setup the model to the site. In order to investigate the impacts of the entire range of soil conditions on ecosystem processes, measurements from the dry and moist plots were used. The data available for the mesic site was excluded since the between-plot variability covered the full range of conditions. The data used are documented in detail below.

\subsubsection{Eddy covariance measurements}

An eddy correlation system by InSituFlux (Ockelbo, Sweden) was installed in 2000 to measure fluxes of $\mathrm{CO}_{2}, \mathrm{H}_{2} \mathrm{O}$, sensible heat, and momentum. The gas analyser was calibrated by an automatic 2-point calibration system for $\mathrm{CO}_{2}$ (Lindroth et al., 2008). Flux data were processed manually by removing spikes based on experiences of this type of measurement (Lindroth et al., 2008). However, the current eddy covariance (EC) data were not gap-filled, which is the major difference to the data used by Lindroth et al. (2008). The eddy flux tower is situated high in the terrain near the dry plots at Knottåsen (Berggren et al., 2004). In the current 
study, hourly values of net ecosystem exchange (NEE), latent heat flux (LE) in 2001 and 2002 and sensible heat flux $(H)$ in 2001, 2002 and 2003 were used.

\subsubsection{Meteorological data}

Hourly meteorological measurements were made from 2001-2003. Global radiation, air temperature, relative humidity, precipitation and wind speed were used as driving variables to the model. Gaps in measurements were filled using data obtained from the nearby official meteorological station within $10 \mathrm{~km}$ from the flux site (Lindroth et al., 2008). This was done after simple use of linear regression for all variables. In the case of precipitation we used snow inventory data to make the best approximation during winter conditions (Berggren et al, 2008).

\subsubsection{Forest inventory data}

The maximum tree height of the 38-year-old spruce stand was $16.5 \mathrm{~m}$ and projected leaf area index was 2.5 in 2001 . The field and ground vegetation was dominated by dwarf shrubs of Vaccinium myrtillus L. and Vaccinium vitis-idaea L., but they were more frequent in dry plots than in moist plots (Berggren et al., 2004).

Biomass measurements in the tree and understory layers were made each year during 2001-2004 (Berggren et al., 2004; Berggren Kleja et al., 2008). Carbon pools in different components of tree and understory layers in the dry and moist plots were estimated. Considering the large differences in vegetation biomass and soil properties in both soil moisture regimes, two initial models were set up based on different initial conditions for dry and moist soil plots, respectively. Average values of carbon pools in 2001 and annual accumulation of carbon during 1999-2001 in the dry and moist plots were calculated separately based on the measurements from the three dry plots and three moist plots, respectively. Average carbon pools in tree and understory layers in 1999 were interpolated and used as the initial values in the respective simulations for the dry and moist soil plots.

Estimated root biomass and annual amounts of litterfall for tree and understory layers during 2001-2002 (Berggren et al., 2004; Berggren Kleja et al., 2008) were used as a reference to estimate reasonable values for different fractions of root biomass and litterfall rate parameters for the dry and moist soil moisture regimes.

\subsubsection{Soil data}

In one dry and one moist plot, soil physical properties, soil temperature, soil moisture, snow depth and water table depth were measured. Soil temperature $\left(T_{\mathrm{S}}\right)$ was measured at a depth of $3 \mathrm{~cm}$ using six replicates, and at 15 and $30 \mathrm{~cm}$ using two replicates. Soil moisture was measured using vertically installed TDR probes at $30 \mathrm{~cm}$ depth with two replicates. Soil moisture content was converted to soil water storage by con- sidering the soil depth. To represent the full range of soil temperature conditions, the warmest replicate of the dry plot and the coldest replicate of the moist plot during 2001-2003 were selected for the modelling study. Water table depth with two replicates and snow depth were measured and the data were recorded automatically.

Soil water retention curves in the organic layer and 10 different mineral layers (at $5 \mathrm{~cm}$ intervals from 0 to $0.5 \mathrm{~m}$ ) were measured in 2003 for the dry and moist plots. These were then used to estimate soil hydraulic properties as represented by the Brooks-Corey equation (Brooks and Corey, 1964) in the simulations.

Mean values of soil carbon pools $(0-1 \mathrm{~m})$ at Knottåsen, $5.48 \mathrm{~kg} \mathrm{~m}^{-2}$ in the three dry plots and $10.4 \mathrm{~kg} \mathrm{~m}^{-2}$ in the three moist plots, were used for the initial values of soil carbon pools (Berggren et al., 2004).

\subsection{Model description and parameterisation}

CoupModel is a one-dimensional physically based model for simulating thermal and hydrological processes, and the corresponding biological processes that regulate carbon and nitrogen transfer in a soil-plant-atmosphere environment (Jansson and Moon, 2001; Jansson and Karlberg, 2009, 2010). In order to maintain systematic consistency in model structures for the studies at Hyytiälä and Knottåsen, the same equations (Table 1) based on the long-term study at Hyytiälä were applied in the current study, namely those regulating plant biotic and abiotic processes, soil carbon and nitrogen processes, soil heat processes, soil water processes, soil evaporation and snow processes.

The model was driven by hourly meteorological data and run during a period from 1999 to 2000 as a pre-simulation period followed by the main investigation period from 2001 to 2003. Hourly mean values were used for 11 validation variables. The soil profile was considered as a depth of $11.3 \mathrm{~m}$, with 20 layers. Lower boundary conditions were specified to allow for differences between the dry and moist conditions by assuming different drainage characteristics.

In order to test model applicability for prediction of photosynthesis and transpiration for a boreal spruce forest in response to cold climate, most prior calibrated parameter ranges in CoupModel for long-term ecosystem processes of Scots pine at Hyytiälä, Finland (Wu et al., 2012) were applied in the current study (Table 2). However, several parameter ranges relating to soil organic decomposition processes and physical properties of Norway spruce and understory were altered to represent the ecosystem conditions at Knottåsen. These parameter ranges were based on previous studies by Berggren Kleja et al. (2008) and Svensson et al. (2008). To distinguish between dry and moist soil plots, the parameters OrganicLayerThick and Drainlevel were given different ranges to represent two different moisture regimes (Table 2). Finally, the effects of nitrogen responses on photosynthesis were simulated as fixed values for this study, since they were 
Table 1. List of equations used in this study.

\begin{tabular}{|c|c|c|}
\hline Equation & No. & Definition \\
\hline \multicolumn{3}{|l|}{ Plant biotic processes } \\
\hline $\begin{array}{l}C_{\mathrm{Atm} \rightarrow a}=f\left(T_{1}\right) f\left(T_{\mathrm{sum}}\right) f\left(\mathrm{CN}_{1}\right) f\left(E_{\mathrm{ta}} / E_{\mathrm{tp}}\right) p_{\max }\left(1-e^{-\varepsilon_{\mathrm{L}} R_{s, \mathrm{pl}} / p_{\max }}\right) \\
\text { where } \varepsilon_{\mathrm{L}} \text { is the radiation use efficiency and } p_{\max } \text { is the maximum level of photosynthesis given a param- } \\
\text { eter. }\end{array}$ & (1) & Rate of photosynthesis $\left(\mathrm{gCm}^{-2} \mathrm{day}^{-1}\right)$ \\
\hline$f\left(T_{1}\right)= \begin{cases}0 & T_{1}<p_{\mathrm{mn}} \\
\left(T_{1}-p_{\mathrm{mn}}\right) /\left(p_{\mathrm{o} 1}-p_{\mathrm{mn}}\right) & p_{\mathrm{mn}} \leq T_{1} \leq p_{\mathrm{o} 1} \\
1 & p_{\mathrm{o} 1<T_{1}<p_{\mathrm{o} 2}} \\
1-\left(T_{1}-p_{\mathrm{o} 2}\right) /\left(p_{\mathrm{mx}}-p_{\mathrm{o} 2}\right) & p_{\mathrm{o} 2} \leq T_{1} \leq p_{\mathrm{mx}} \\
0 & T_{1}>p_{\mathrm{mx}}\end{cases}$ & (2) & Response function for leaf temperature (-) \\
\hline $\begin{array}{l}\text { where } p_{\mathrm{mn}}, p_{\mathrm{o} 1}, p_{\mathrm{o} 2} \text { and } p_{\mathrm{mx}} \text { are parameters. } \\
f\left(\mathrm{CN}_{l}\right)=p_{\text {fixedN }} \\
\text { where } p_{\text {fixedN }} \text { is a parameter. }\end{array}$ & (3) & Response function for fixed leaf $\mathrm{C}: \mathrm{N}$ ratio $(-)$ \\
\hline$f\left(E_{\mathrm{ta}} / E_{\mathrm{tp}}\right)=\frac{E_{\mathrm{ta}}}{E_{\mathrm{tp}}}$ & (4) & Response function for transpiration (-) \\
\hline \multicolumn{3}{|l|}{$\begin{array}{l}\text { where } p_{T \text { sum,start }} \text { and } p_{T \text { sum,opt }} \text { are parameters, } T \text { sum growing is cumulative temperature sum during the } \\
\text { growing season. }\end{array}$} \\
\hline $\begin{array}{l}C_{\text {respleaf }}=k_{\text {mrespleaf }} \cdot f\left(T_{\mathrm{a}}\right) \cdot C_{\text {leaf }}+k_{\text {gresp }} \cdot C_{a \rightarrow \text { Leaf }} \\
\text { where } k_{\text {mrespleaf }} \text { is the maintenance respiration coefficient for leaves, } k_{\text {gresp }} \text { is the growth respiration } \\
\text { coefficient, and } f\left(T_{\mathrm{a}}\right) \text { is the temperature response function for maintenance respiration. The equation } \\
\text { calculates respiration from stem, roots, and grains by exchanging } k_{\text {mrespleaf }} \text { to } k_{\text {mrespstem }}, k_{\text {mresproot }} \text {, } \\
k_{\text {mrespgrain }} \text {, and using the corresponding storage pools. Respiration from the old carbon pools is estimated } \\
\text { with the same maintenance respiration coefficients as for respiration from new carbon pools. }\end{array}$ & (6) & $\begin{array}{l}\text { Plant growth and maintenance respiration from leaves } \\
\left(\mathrm{g} \mathrm{C} \mathrm{m}^{-2} \mathrm{day}^{-1}\right)\end{array}$ \\
\hline $\begin{array}{l}f\left(T_{\mathrm{a}}\right)=t_{Q 10}^{\left(T-t_{Q 10 \mathrm{bas}}\right) / 10} \\
\text { where } t_{Q 10} \text { and } t_{Q 10 \mathrm{bas}} \text { are parameters. }\end{array}$ & (7) & Temperature response function for maintenance respiration (-) \\
\hline $\begin{array}{l}N_{\mathrm{Atm} \rightarrow \mathrm{NH}}=p_{\mathrm{dry}} p_{\mathrm{fNH}, \text { Dry }}+p_{\mathrm{cwet}} p_{\mathrm{fNH}}, \text { Wet } \\
q_{\mathrm{in}} \\
\text { where } p_{\mathrm{dry}}, p_{\mathrm{fNH} 4, \mathrm{Dry}}, p_{\mathrm{cwet}} \text { and } p_{\mathrm{fNH} 4} \text {,Wet are site-specific parameters and } q_{\text {in }} \text { is the water infiltration } \\
\text { rate. }\end{array}$ & (8) & Ammonium deposition to the soil \\
\hline $\begin{array}{l}N_{\mathrm{Atm} \rightarrow \mathrm{NO}}=p_{\mathrm{dry}} p_{\mathrm{fNH}, \mathrm{Dry}}+p_{\mathrm{cwet}} p_{\mathrm{fNH}, \text { Wet }} q_{\text {in }} \\
\text { where } p_{\mathrm{dry}}, p_{\mathrm{fNH} 4, \mathrm{Dry}}, p_{\mathrm{cwet}} \text { and } p_{\mathrm{fNH} 4, \text { Wet }} \text { are site-specific parameters and } q_{\text {in }} \text { is the water infiltration } \\
\text { rate. }\end{array}$ & (9) & Nitrate deposition to the soil \\
\hline \multicolumn{3}{|l|}{ Plant abiotic processes } \\
\hline $\begin{array}{l}R_{s, \mathrm{pl}}=\left(1-e^{-k_{\mathrm{rn}} \frac{A_{\mathrm{l}}}{f_{\mathrm{cc}}}}\right) \cdot f_{\mathrm{cc}}\left(1-a_{\mathrm{pl}}\right) R_{\mathrm{is}} \\
\text { where } k_{\mathrm{rn}} \text { is the light use extinction coefficient given as a single parameter common for all plants, } f_{\mathrm{cc}} \text { is } \\
\text { the surface canopy cover, and } a_{\mathrm{pl}} \text { is the plant albedo. }\end{array}$ & $(10)$ & $\begin{array}{l}\text { Plant interception of global radiation } \\
\left(\mathrm{MJ} \mathrm{m}^{-2} \mathrm{day}^{-1}\right)\end{array}$ \\
\hline $\begin{array}{l}f_{\mathrm{cc}}=p_{\mathrm{c} \max }\left(1-e^{-p_{\mathrm{ck}} A_{1}}\right) \\
\text { where } p_{\mathrm{cmax}} \text { is a parameter that determines the maximum surface cover and } p_{\mathrm{ck}} \text { is a parameter the } \\
\text { governs the speed at which the maximum surface cover is reached. } A_{1} \text {. is the leaf area index of the plant. }\end{array}$ & $(11)$ & Surface canopy cover $\left(\mathrm{m}^{2} \mathrm{~m}^{-2}\right)$ \\
\hline $\begin{array}{l}A_{1}=\frac{B_{1}}{p_{l, \mathrm{sp}}} \\
\text { where } p_{l, \mathrm{sp}} \text { is a parameter and } B_{1} \text { is the total mass of leaf. }\end{array}$ & $(12)$ & Leaf area index $\left(\mathrm{m}^{2} \mathrm{~m}^{-2}\right)$ \\
\hline $\begin{array}{l}S_{\text {imax }}=i_{\mathrm{LAI}} A_{1}+i_{\text {base }} \\
\text { where } i_{\mathrm{LAI}} \text { and } i_{\text {base }} \text { are parameters. }\end{array}$ & (13) & Interception storage $(\mathrm{mm})$ \\
\hline Equation & No. & Definition \\
\hline $\begin{array}{l}E_{\mathrm{ta}}^{*}=E_{\mathrm{tp}}^{*} \int f(\psi(z)) f(T(z)) r(z) \\
\text { where } r(z) \text { is the relative root density distribution, } z \text { is root depth and } f(\psi(z)) \text { and } f(T(z)) \text { are response } \\
\text { functions for soil water potential and soil temperature. }\end{array}$ & (14) & Actual transpiration before compensatory uptake $\left(\mathrm{mmday}^{-1}\right)$ \\
\hline $\begin{array}{l}E_{\mathrm{ta}}=E_{\mathrm{ta}}^{*}+f_{\mathrm{umov}} \cdot\left(E_{\mathrm{tp}}^{*}-E_{\mathrm{ta}}^{*}\right) \\
\text { where } f_{\mathrm{umov}} \text { is the degree of compensation, } E_{\mathrm{ta}}^{*} \text { is the uptake without any account of compensatory } \\
\text { uptake, and } E_{\mathrm{tp}}^{*} \text { is the potential transpiration with eventual reduction due to interception evaporation. }\end{array}$ & $(15)$ & Actual transpiration $\left(\mathrm{mmday}^{-1}\right)$ \\
\hline $\begin{array}{l}f(\psi(z))=\min \left(\left(\frac{\psi_{c}}{\psi(z)}\right)^{p_{1} E_{\mathrm{tp}}+p_{2}}, f_{\theta}\right) \\
\text { where } p_{1}, p_{2} \text { and } \psi_{c} \text { are parameters, and an additional response function, } f_{\theta} \text {, corresponds to the normal } \\
\text { need of oxygen supply to fine roots. }\end{array}$ & $(16)$ & Response function for soil water potential (-) \\
\hline $\begin{array}{l}f(T(z))= \begin{cases}1-e^{-t_{\mathrm{WA}} \max \left(0, T(z)-T_{\text {trig }}\right)^{t} \mathrm{WB}} & I_{\text {day }} \leq p_{\text {daycut }} \\
1 & I_{\text {day }}>p_{\text {daycut }}\end{cases} \\
\text { where } t_{\mathrm{WA}}, p_{\text {daycut }} \text { and } t_{\mathrm{WB}} \text { are parameters. } T_{\text {trig }} \text { is the trigger temperature. }\end{array}$ & $(17)$ & Response function for soil temperature (-) \\
\hline $\begin{array}{l}L_{v} E_{\mathrm{tp}}=\frac{\Delta R_{\mathrm{n}}+\rho_{\mathrm{a}} c_{\mathrm{p}} \frac{\left(e_{\mathrm{s}}-e_{\mathrm{a}}\right)}{r_{\mathrm{a}}}}{\Delta+\gamma\left(1+\frac{r_{\mathrm{s}}}{r_{\mathrm{a}}}\right)} \\
\text { where } R_{\mathrm{n}} \text { is net radiation available for transpiration, } e_{\mathrm{S}} \text { is the vapour pressure at saturation, } e_{\mathrm{a}} \text { is the actual } \\
\text { vapour pressure, } \rho_{\mathrm{a}} \text { is air density, } c_{\mathrm{p}} \text { is the specific heat of air at constant pressure, } L_{v} \text { is the latent heat of } \\
\text { vaporisation, } \Delta \text { is the slope of saturated vapour pressure versus temperature curve, } \gamma \text { is the psychrometer } \\
\text { "constant", } r_{\mathrm{s}} \text { is "effective" surface resistance and } r_{\mathrm{a}} \text { is the aerodynamic resistance. }\end{array}$ & (18) & Potential transpiration $\left(\mathrm{mmday}^{-1}\right)$ \\
\hline $\begin{array}{l}r_{\mathrm{S}}=\frac{1}{\max \left(A_{1} g_{1}, 0.001\right)} \\
\text { where } g_{1} \text { is the leaf conductance. }\end{array}$ & (19) & Stomatal resistance $\left(\mathrm{s} \mathrm{m}^{-1}\right)$ \\
\hline $\begin{array}{l}g_{1}=\frac{R_{\mathrm{is}}}{R_{\mathrm{is}}+g_{\mathrm{ris}}} \frac{g_{\max }}{1+\frac{\left(e_{\mathrm{s}}-e_{\mathrm{a}}\right)}{g_{\mathrm{vpd}}}} \\
\text { where } g_{\text {ris }}, g_{\max } \text { and } g_{\mathrm{vpd}} \text { are parameter values. }\end{array}$ & $(20)$ & $\begin{array}{l}\text { Stomatal conductance per leaf area } \\
\left(\mathrm{ms}^{-1}\right)\end{array}$ \\
\hline
\end{tabular}


Table 1. Continued.

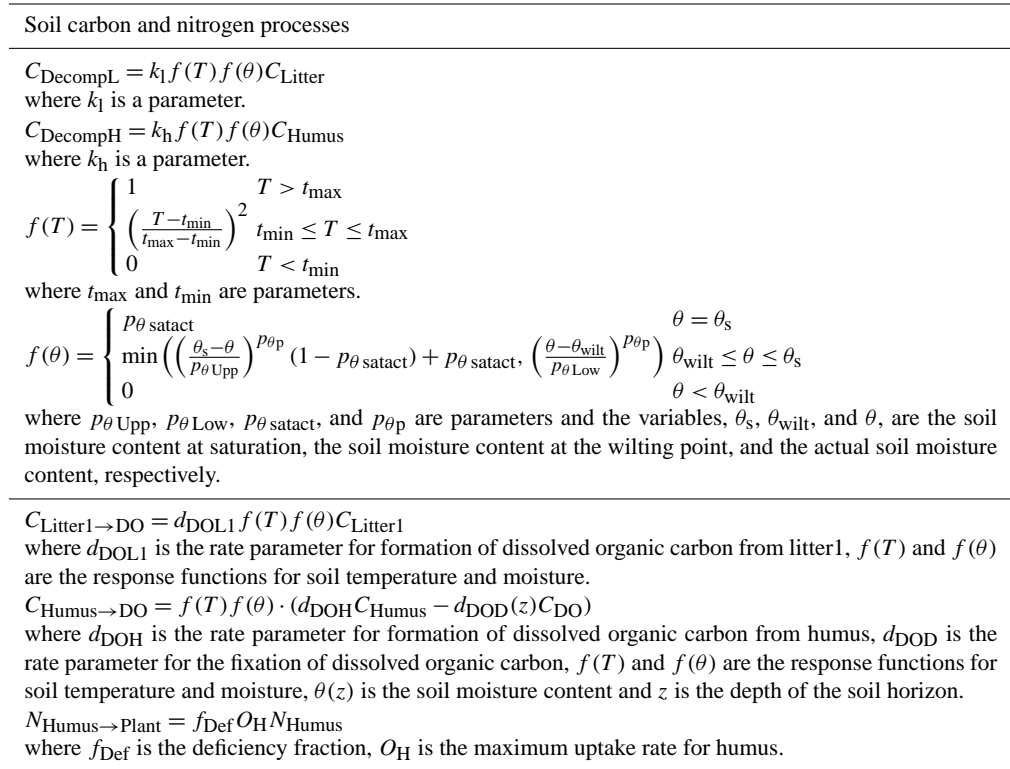

(21) Decomposition of litter $\left(\mathrm{gCm}^{-2} \mathrm{day}^{-1}\right)$

(22) Decomposition of humus $\left(\mathrm{g} \mathrm{Cm}^{-2} \mathrm{day}^{-1}\right)$

(23) Response function for soil temperature (Ratkowsky function) (-)

(24) Response function for soil moisture (-)

(25) The flux from litter to dissolved organic carbon $\left(\mathrm{gCm}^{-2} \mathrm{day}^{-1}\right)$

(26) The flux from humus to dissolved organic carbon $\left(\mathrm{gCm}^{-2}\right.$ day $\left.^{-1}\right)$

(27) The organic nitrogen flux from humus to the plant $\left(\mathrm{g} \mathrm{N} \mathrm{m}^{-2} \mathrm{day}^{-1}\right)$

Soil heat processes

$q_{\mathrm{h}}(0)=k_{\mathrm{ho}} \frac{\left(T_{\mathrm{s}}-T_{1}\right)}{\Delta z / 2}+C_{\mathrm{W}}\left(T_{\mathrm{a}}-\Delta T_{\mathrm{Pa}}\right) q_{\mathrm{in}}+L_{\mathrm{v}} q_{\mathrm{vo}}$

where $k_{\mathrm{ho}}$ is the conductivity of the organic material at the surface, $T_{\mathrm{S}}$ is the surface temperature, $T_{1}$ is the temperature in the uppermost soil layer, $\Delta T_{\mathrm{Pa}}$ is a parameter that represents the temperature difference between the air and the precipitation, $q_{\mathrm{in}}$, is the water infiltration rate, $q_{\mathrm{vo}}$ is the water vapour flow, and $L_{\mathrm{V}}$ is the latent heat. The temperature difference, $T_{\mathrm{a}}-\Delta T_{\mathrm{Pa}}$, can optionally be exchanged to surface temperature, $T_{\mathrm{S}}$

$\left.T_{\mathrm{b}}=\frac{T_{1}+\left(\frac{k_{\mathrm{ho}}\left(\Delta z_{1} / 2-\Delta z_{\text {humus }}\right)}{k_{\mathrm{hm}} \Delta z_{\text {humus }}}\right)}{1+\left(\frac{k_{\mathrm{ho}}\left(\Delta z_{1} / 2-\Delta z_{\text {humus }}\right)}{k_{\mathrm{hm}} \Delta z_{\text {humus }}}\right)}\right) T_{\mathrm{s}}$

(29) The boundary temperature between humus and mineral soil in

the thickness of the humus layer.

Soil water processes

$S_{\mathrm{e}}=\left(\frac{\psi}{\psi_{\mathrm{a}}}\right)^{-\lambda}$

where $\psi_{\mathrm{a}}$ is the air-entry tension, $\psi$ is the pressure head or actual water tension, and $\lambda$ is the pore size distribution index.

$q_{\mathrm{wp}}=\int_{z_{\mathrm{p}}}^{z_{\mathrm{sat}}} k_{\mathrm{s}} \frac{\left(z_{\mathrm{sat}}-z_{p}\right)}{d_{\mathrm{u}} d_{\mathrm{p}}} \mathrm{d}_{z}$

where $k_{\mathrm{sat}}$ is the saturated conductivity, $d_{\mathrm{u}}$ is the unit length of the horizontal element, $z_{\mathrm{p}}$ is the lower depth of the drainage pipe, $z_{\text {sat }}$ is the simulated depth of the water table, and $d_{\mathrm{p}}$ is a characteristic distance between drainage pipes. the top soil layer $\left({ }^{\circ} \mathrm{C}\right)$

(28) Soil surface heat flow $\left(\mathrm{J} \mathrm{m}^{-2} \mathrm{day}^{-1}\right)$

(30) The effective saturation (-)

(31) Groundwater outflow $\left(\mathrm{mmday}^{-1}\right)$

Soil evaporation and snow processes

\section{$R_{\mathrm{ns}}=L_{\mathrm{V}} E_{\mathrm{s}}+H_{\mathrm{s}}+q_{\mathrm{h}}$}

where $L_{\mathrm{V}} E_{\mathrm{S}}$ is the sum of latent heat flux, $H_{\mathrm{S}}$ is the sensible heat flux, and $q_{\mathrm{h}}$ is the heat flux to soil. $L_{\mathrm{V}} E_{\mathrm{S}}=\frac{\rho_{\mathrm{a}} c_{\mathrm{p}}}{\gamma} \frac{\left(e_{\mathrm{surf}}-e_{\mathrm{a}}\right)}{r_{\mathrm{as}}}$

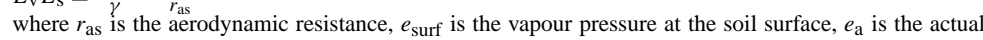
vapour pressure in air, $\rho_{\mathrm{a}}$ is the air density, $c_{\mathrm{p}}$ heat capacity of air, $L_{\mathrm{V}}$ the latent heat of vaporisation, and $\gamma$ is the psychometric constant. $e_{\text {surf }}=e_{\mathrm{S}}\left(T_{\mathrm{S}}\right) e^{\left(\frac{\psi M_{\text {water }} g e_{\text {corr }}}{R\left(T_{\mathrm{S}}+273.15\right)}\right)}$

where $e_{\mathrm{S}}$ is the vapour pressure at saturation at soil surface temperature $T_{\mathrm{S}}, \psi$ is the soil water tension and $g$ is the gravitational constant, $R$ is the gas constant, $M_{\text {water }}$ is the molar mass of water and $e_{\text {corr }}$ is the empirical correction factor.

$e_{\text {corr }}=10^{\left(-\delta_{\text {surf }} \psi_{\text {eg }}\right)}$

where $\psi_{\text {eg }}$ is a parameter and $\delta_{\text {surf }}$ is a calculated mass balance at the soil surface.

$M=M_{\mathrm{T}} T_{\mathrm{a}}+M_{\mathrm{R}} R_{\mathrm{is}}+\frac{f_{\mathrm{qh}} q_{\mathrm{h}}(0)}{L_{\mathrm{f}}}$

where $T_{\mathrm{a}}$ is air temperature, $R_{\mathrm{is}}$ is global radiation, $f_{\mathrm{qh}}$ is a scaling coefficient, and $L_{\mathrm{f}}$ is the latent heat of freezing.

$M_{\mathrm{T}}= \begin{cases}m_{\mathrm{T}} & T_{\mathrm{a}} \geq 0 \\ \frac{m_{\mathrm{T}}}{\Delta z_{\text {snow }} m_{\mathrm{f}}} & T_{\mathrm{a}}<0\end{cases}$

where $T_{\mathrm{a}}$ is air temperature and $m_{\mathrm{T}}$ and $m_{\mathrm{f}}$ are parameters.

$M_{\mathrm{R}}=m_{\mathrm{Rmin}}\left(1+s_{1}\left(1-e^{-s_{2} s_{\mathrm{age}}}\right)\right)$

where $m_{\mathrm{Rmin}}, s_{1}$. and $s_{2}$. are parameters.
(32) Surface energy balance approach $\left(\mathrm{Jm}^{-2} \mathrm{day}^{-1}\right)$

(33) Latent heat flux $\left(\mathrm{Jm}^{-2} \mathrm{day}^{-1}\right)$

(34) Vapour pressure head at the soil surface ( $\mathrm{cm}$ water)

(35) Empirical correction factor (-)

(36) The amount of snow melt $\left(\mathrm{kg} \mathrm{m}^{-2} \mathrm{day}^{-1}\right)$

(37) Temperature function $\left(\mathrm{kg}^{\circ} \mathrm{C}^{-1} \mathrm{~m}^{-2}\right.$ day $\left.^{-1}\right)$

(38) Solar radiation function $\left(\mathrm{kg} \mathrm{J}^{-1}\right)$ 
Table 1. Continued.

\begin{tabular}{|c|c|c|}
\hline Equation & No. & Definition \\
\hline 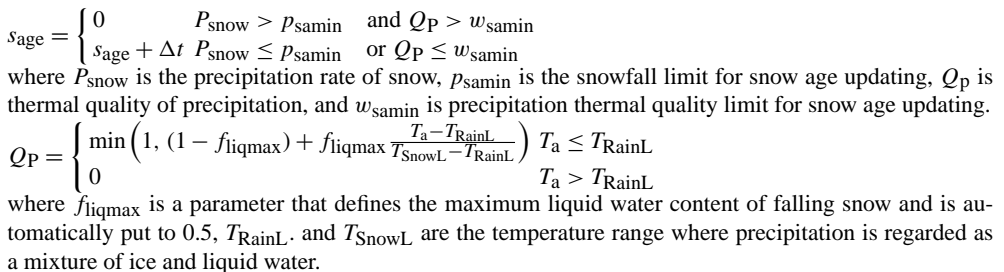 & $(40)$ & Thermal quality of precipitation (-) \\
\hline $\begin{array}{l}\rho_{\text {snow }}=\frac{\rho_{\text {prec }} \Delta z_{\text {prec }}+\rho_{\text {old }} \Delta z_{\text {old }}}{\Delta z_{\text {snow }}} \\
\text { where } \Delta z \text { indicates depth and the indices old, prec, snow represent old snow pack, precipitation, and } \\
\text { updated snow pack. }\end{array}$ & $(41)$ & Snow density $\left(\mathrm{kg} \mathrm{m}^{-2}\right)$ \\
\hline $\begin{array}{l}\rho_{\mathrm{old}}=\rho_{\mathrm{smin}}+s_{\mathrm{dl}} \frac{S_{\mathrm{wl}}}{S_{\mathrm{wlmax}}}+s_{\mathrm{dw}} S_{\mathrm{res}} \\
\text { where } \rho_{\mathrm{smin}} \text { is the density of new snow, } s_{\mathrm{dl}} \text { and } s_{\mathrm{dw}} \text { are parameters, } S_{\mathrm{wl}} \text { is the retention capacity, } S_{\mathrm{wlmax}} \\
\text { is the maximum of retention capacity, and } S_{\mathrm{res}} \text { is the water equivalent of the snow. }\end{array}$ & $(42)$ & Density of old snow pack $\left(\mathrm{kgm}^{-2}\right)$ \\
\hline
\end{tabular}

similar to using the dynamic nitrogen response, according to experiences from simulating both fixed and dynamic nitrogen responses at Hyytiälä (Wu et al., 2012).

The Generalised Likelihood Uncertainty Estimation (GLUE; Beven, 2006) was applied to explore uncertainties in parameters, model assumptions and measurements using a Monte Carlo-based sampling of parameter values and selection of behavioural models on subjective multiple criteria using informal performance indices.

In order to investigate the importance of $T_{\mathrm{S}}$ response function effects on photosynthesis and transpiration, simulations with and without the $T_{\mathrm{s}}$ response function were conducted in parallel (Eq. 1) in Table 1. Without the $T_{\mathrm{s}}$ response function $\left(T_{\mathrm{s}}\right.$ response $\left.=1\right)$, the three parameters TempCoefA, TempCoefC and TempWupDayNocut were set to fixed values and removed from the GLUE calibration list.

In summary, four different general model assumptions were set up, representing dry/moist conditions (Dry/Moist) and with and without the $T_{\mathrm{S}}$ response functions ( $T_{\mathrm{S}}$ and NoTs). A set of 10000 simulations was conducted for each of these four general model assumptions.

\subsection{Performance indices}

The two performance indices, coefficient of determination $\left(R^{2}\right)$ and mean error (ME), allowed behavioural models to be identified with respect to dynamics and mean values of the fluxes. In the first step, the behavioural simulation was selected on the flux data only (criteria $\mathrm{C} 1$ ), but then we also constrained the data by soil temperature to distinguish between the dry and moist plots (criteria C2). Namely, C1 was composed of only EC fluxes: heat $(H)$, water vapour (LE), and carbon (NEE) fluxes. In $\mathrm{C} 1, R^{2}$ was $<0.6$ for $H, \mathrm{LE}$ and NEE. Accordingly, for ME the range was $\pm 11.56 \mathrm{~W} \mathrm{~m}^{-2}$ (equal to $\pm 1.0 \mathrm{MJ} \mathrm{m}^{-2} \mathrm{day}^{-1}$ ) for $H$ and $\mathrm{LE}$, while for NEE it was $\pm 0.4 \mathrm{~g} \mathrm{C} \mathrm{m}^{-2}$ day $^{-1}$. $\mathrm{C} 2$ was composed of EC fluxes with $T_{\mathrm{s}}$ at a depth of $3 \mathrm{~cm}$. When $\mathrm{C} 2$ constrained simulations in the dry plot, $T_{\mathrm{s}}$ at the warmest position was used. On the other hand, when $\mathrm{C} 2$ constrained simulations in the moist plot, $T_{\mathrm{S}}$ at the coldest position was used. In $\mathrm{C} 2, R^{2}$ was $>0.6$ for $H, \mathrm{LE}$ and NEE and $>0.8$ for $T_{\mathrm{S}}$ with $\mathrm{ME}$ in the range $\pm 11.56 \mathrm{~W} \mathrm{~m}^{-2}$ (equal to $\pm 1.0 \mathrm{MJ} \mathrm{m}^{-2} \mathrm{day}^{-1}$ ) for $H$ and LE, and $\pm 0.4 \mathrm{~g} \mathrm{C} \mathrm{m}^{-2} \mathrm{day}^{-1}$ for NEE and $\pm 1^{\circ} \mathrm{C}$ for $T_{\mathrm{s}}$.

\section{Results and discussion}

\subsection{Climate conditions and spatial variability in soil temperature, soil moisture and biomass}

At Knottåsen, the mean annual air temperature was 3.8, 4.5 and $4.5^{\circ} \mathrm{C}$ in 2001,2002 and 2003 , respectively, which was warmer than the 30-yr (1961-1990) mean annual air temperature of $3.4^{\circ} \mathrm{C}$. In contrast, the mean annual precipitation was 588, 533 and $512 \mathrm{~mm}$ in 2001, 2002 and 2003, respectively, which is lower than the $30-y r$ mean annual precipitation of $613 \mathrm{~mm}$. Global radiation $\left(R_{\mathrm{g}}\right)$ was similar for all the years, with a maximum value of $\sim 300 \mathrm{~W} \mathrm{~m}^{-2}$ in summer. Air temperature $\left(T_{\mathrm{a}}\right)$ reached its lowest values $\left(\sim-20^{\circ} \mathrm{C}\right)$ in winter and its highest values $\left(\sim+20^{\circ} \mathrm{C}\right)$ in summer (Fig. 1). The growing season $\left(5^{\circ} \mathrm{C}\right.$ threshold $)$ normally started in late April. Seasonal patterns of precipitation during 2001-2003 were different from year to year. For instance, high intensity rainstorms occurred frequently in autumn 2001 and summer 2002, which caused corresponding drops in $R_{\mathrm{g}}$ and $T_{\mathrm{a}}$. In 2001 precipitation occurred as snow during the whole winter and lasted until early May, but very few snow events happened in early spring (March and April) in 2002 and 2003.

Spatial variability of soil conditions such as soil temperature, soil water storage, water table and snow depth was reflected by the measurements from the plots defined by different moisture regimes at Knottåsen (Berggren et al., 2004). Soil temperature in the dry plot was generally higher than $T_{\mathrm{s}}$ in the moist plot during the growing season but lower in winter (Fig. 2). The moist plot also showed the highest variability range, both within and between years. For both the dry and moist plots the dynamics of the variability showed irregular patterns, with typical peaks in all seasons, but the 
Table 2. List of parameters for the GLUE calibration procedure.

\begin{tabular}{|c|c|c|c|c|c|}
\hline Parameter & Unit & Symbol & $\begin{array}{l}\text { Eq./Note } \\
\text { (Table 1) }\end{array}$ & \multicolumn{2}{|c|}{ Prior } \\
\hline \multicolumn{6}{|l|}{ Plant biotic processes } \\
\hline $\operatorname{RadEfficiency}(1)^{\mathrm{a}}$ & $\mathrm{gDw} \mathrm{MJ}^{-1}$ & & Eq. (1) & 2 & 4 \\
\hline $\operatorname{RadEfficiency}(2)^{\mathrm{a}}$ & $\mathrm{g} \mathrm{Dw} \mathrm{MJ}^{-1}$ & & $\begin{array}{l}\text { Eq. (1)/Same } \\
\text { as RadEffi- } \\
\text { ciency }(1)^{b}\end{array}$ & 2 & 4 \\
\hline $\operatorname{Pmax}(1)$ & $\mathrm{gCm}^{-2} \mathrm{day}^{-1}$ & $p_{\max }$ & Eq. (1) & 20 & 40 \\
\hline $\operatorname{Pmax}(2)$ & $\mathrm{gCm}^{-2} \mathrm{day}^{-1}$ & $p_{\max }$ & $\begin{array}{l}\text { Eq. (1)/Same as } \\
\operatorname{Pmax}(1)\end{array}$ & 20 & 40 \\
\hline T LMin(1) & ${ }^{\circ} \mathrm{C}$ & $p_{\mathrm{mn}}$ & Eq. (2) & -8 & 0 \\
\hline T LOpt1(1) & ${ }^{\circ} \mathrm{C}$ & $p_{\mathrm{o} 1}$ & Eq. (2) & 5 & 15 \\
\hline $\mathrm{T} \operatorname{LMin}(2)$ & ${ }^{\circ} \mathrm{C}$ & $p_{\mathrm{mn}}$ & $\begin{array}{l}\text { Eq. (2)/Same as } \\
\text { T LMin(1) }\end{array}$ & -8 & 0 \\
\hline T LOpt1(2) & ${ }^{\circ} \mathrm{C}$ & $p_{\mathrm{o} 1}$ & $\begin{array}{l}\text { Eq. (2)/Same as } \\
\text { T LOpt1(1) }\end{array}$ & 5 & 15 \\
\hline FixN supply(1) & - & $p_{\text {fixedN }}$ & Eq. (3 a) & 0.5 & 1 \\
\hline FixN supply(2) & - & $p_{\text {fixedN }}$ & Eq. (3 a) & 0.5 & 1 \\
\hline TF Sum Start(1) & - & $p_{\text {Tsum, start }}$ & Eq. (5) & 0.3 & 1 \\
\hline T Sum Opt(1) & ${ }^{\circ} \mathrm{C}$ & $p_{\text {Tsum,opt }}$ & Eq. (5) & 100 & 400 \\
\hline TF Sum Start(2) & - & $p_{\text {Tsum, start }}$ & $\begin{array}{l}\text { Eq. (5)/Same as } \\
\text { TF Sum Start(1) }\end{array}$ & 0.3 & 1 \\
\hline T Sum Opt(2) & ${ }^{\circ} \mathrm{C}$ & $p_{\text {Tsum,opt }}$ & $\begin{array}{l}\text { Eq. (5)/Same as } \\
\text { T Sum Opt(1) }\end{array}$ & 100 & 400 \\
\hline RespTemQ10 & - & $t_{\mathrm{Q} 10}$ & Eq. (7) & 1.5 & 2.5 \\
\hline Dep N WetConc & $\mathrm{mgN1}^{-1}$ & $p_{\text {cwet }}$ & Eq. (8)/(9) & 0.8 & 1.2 \\
\hline \multicolumn{6}{|l|}{ Plant abiotic processes } \\
\hline Area $k \operatorname{Exp}(2)$ & - & $p_{\mathrm{ck}}$ & Eq. (11) & 1 & 2 \\
\hline Specific LeafArea $(1)^{\mathrm{c}}$ & $\mathrm{gCm}^{-2}$ & $p_{1, \mathrm{sp}}$ & Eq. (12) & 90 & 150 \\
\hline Specific LeafArea(2) ${ }^{c}$ & $\mathrm{gCm}^{-2}$ & $p_{1, \mathrm{sp}}$ & Eq. (12) & 20 & 60 \\
\hline WaterCapacityPerLAI & $\mathrm{mm} \mathrm{m}^{-2}$ & $i_{\mathrm{LAI}}$ & Eq. (13) & 0.05 & 0.1 \\
\hline CritThresholdDry & $\mathrm{cm}$ water & $\psi_{\mathrm{c}}$ & Eq. (16) & 100 & $1.0 \times 10^{4}$ \\
\hline TempCoefA & - & $t_{\mathrm{WA}}$ & Eq. (17) & 0.2 & 1.5 \\
\hline TempCoefC & - & $T_{\text {trig }}$ & Eq. (17) & -2 & 2 \\
\hline TempWupDayNoCut & - & $P_{\text {daycut }}$ & Eq. (17) & 270 & 366 \\
\hline Conduct Ris(1) & $\mathrm{Jm}^{-2}$ day $^{-1}$ & $g_{\text {ris }}$ & Eq. (20) & $1.0 \times 10^{6}$ & $1.0 \times 10^{7}$ \\
\hline Conduct VPD(1) & $\mathrm{Pa}$ & $g_{\text {vpd }}$ & Eq. (20) & 50 & 300 \\
\hline Conduct Max(1) & $\mathrm{ms}^{-1}$ & $g_{\max }$ & Eq. (20) & $5.0 \times 10^{-3}$ & 0.03 \\
\hline CondMaxWinter & $\mathrm{ms}^{-1}$ & $g_{\text {max winter }}$ & Eq. (20) & $2.0 \times 10^{-3}$ & $6.0 \times 10^{-3}$ \\
\hline \multicolumn{6}{|c|}{ Soil carbon and nitrogen processes } \\
\hline RateCoefLitter ${ }^{\mathrm{c}}$ & day $^{-1}$ & $k_{1}$ & Eq. (21) & $5.0 \times 10^{-3}$ & 0.05 \\
\hline RateCoefHumus ${ }^{\mathrm{c}}$ & day $^{-1}$ & $k_{\mathrm{h}}$ & Eq. (22) & $6.0 \times 10^{-5}$ & $6.0 \times 10^{-4}$ \\
\hline TempMin & ${ }^{\circ} \mathrm{C}$ & $t_{\min }$ & Eq. (23) & -10 & 0 \\
\hline TempMax & ${ }^{\circ} \mathrm{C}$ & $t_{\max }$ & Eq. (23) & 20 & 30 \\
\hline SaturationActivity & - & $p_{\mathrm{qSatact}}$ & Eq. (24) & 0 & 0.6 \\
\hline ThetaLowerRange & $\%$ & $p_{\mathrm{qLow}}$ & Eq. (24) & 3 & 20 \\
\hline RateCoefLitter1Dis ${ }^{c}$ & day $^{-1}$ & $d_{\mathrm{DOH}}$ & Eq. (25) & $1.0 \times 10^{-5}$ & 0.01 \\
\hline RateCoefHumusDis & day $^{-1}$ & $d_{\mathrm{DOL} 1}$ & Eq. (26) & $1.0 \times 10^{-6}$ & $1.0 \times 10^{-3}$ \\
\hline Upt OrgRateCoef H & - & $O_{\mathrm{H}}$ & Eq. (27) & 0 & $5.0 \times 10^{-4}$ \\
\hline
\end{tabular}


Table 2. Continued.

\begin{tabular}{|c|c|c|c|c|c|}
\hline Parameter & Unit & Symbol & $\begin{array}{l}\text { Eq./Note } \\
\text { (Table 1) }\end{array}$ & $\begin{array}{l}\text { Prior } \\
\text { Min }\end{array}$ & Max \\
\hline \multicolumn{6}{|l|}{ Soil heat processes } \\
\hline OrganicLayerThick $^{\mathrm{c}}$ & $\mathrm{m}$ & $\Delta z_{\text {humus }}$ & Eq. (29) & $5.0 \times 10^{-3 \mathrm{~d}} / 0.05^{\mathrm{e}}$ & $0.1^{\mathrm{d}} / 0.2^{\mathrm{e}}$ \\
\hline ThScaleLog $(0-0.05 \mathrm{~m})$ & - & $x_{\mathrm{hf}}$ & $\begin{array}{l}\text { A scaling coeffi- } \\
\text { cient for thermal } \\
\text { conductivity for } \\
\text { each soil layer }\end{array}$ & -0.7 & 0.3 \\
\hline ThScaleLog $(0.15-0.25 \mathrm{~m})$ & - & $x_{\mathrm{hf}}$ & & -0.7 & 0.3 \\
\hline ThScaleLog $(0.5-0.7 \mathrm{~m})$ & - & $x_{\mathrm{hf}}$ & & -0.7 & 0.3 \\
\hline \multicolumn{6}{|l|}{ Soil water processes } \\
\hline Air Entry(0-0.05 m) & $\mathrm{cm}$ water & $\psi_{\mathrm{a}}$ & Eq. (30) & 1 & 10 \\
\hline Air Entry $(0.05-0.15 \mathrm{~m})$ & $\mathrm{cm}$ water & $\psi_{\mathrm{a}}$ & Eq. (30) & 1 & 10 \\
\hline DrainLevel $^{c}$ & $\mathrm{~m}$ & $z_{\mathrm{p}}$ & Eq. (31) & $-2.5^{\mathrm{d}} /-1.5^{\mathrm{e}}$ & $-1^{\mathrm{d}} /-0.1^{\mathrm{e}}$ \\
\hline \multicolumn{6}{|c|}{ Soil evaporation and snow processes } \\
\hline EquilAdjustPsi & - & $\psi_{\mathrm{eg}}$ & Eq. (35) & 1 & 4 \\
\hline MeltCoefAirTemp & $\mathrm{kg}^{\circ} \mathrm{C}^{-1} \mathrm{~m}^{-2}$ day $^{-1}$ & $m_{\mathrm{T}}$ & Eq. (37) & 1 & 3 \\
\hline MeltCoefGlobRad & $\mathrm{kg} \mathrm{J}^{-1}$ & $m_{\mathrm{Rmin}}$ & Eq. (38) & 0 & $3.0 \times 10^{-7}$ \\
\hline OnlyRainPrecTemp & ${ }^{\circ} \mathrm{C}$ & $T_{\text {RainL }}$ & Eq. (40) & 0 & 4 \\
\hline OnlySnowPrecTemp & ${ }^{\circ} \mathrm{C}$ & $T_{\text {SnowL }}$ & Eq. (40) & -3 & 0 \\
\hline DensityOfNewSnow & $\mathrm{kg} \mathrm{m}^{-3}$ & $\rho_{\mathrm{smin}}$ & Eq. (42) & 75 & 125 \\
\hline DensityCoefWater & $\mathrm{kg} \mathrm{m}^{-3}$ & $S_{\mathrm{dl}}$ & Eq. (42) & 50 & 200 \\
\hline
\end{tabular}

highest variability normally occurred in winter and spring. This suggests that snow cover was distributed unevenly in winter due to position in the landscape, canopy density and different exposure to radiation. Soil moisture was depleted much faster from May-August in 2001 compared with 2002 and 2003 in both plots. Due to frequent high-intensity precipitation in July 2002, soil moisture storage was recharged rapidly. In 2003 soil water storage in the moist plot was much higher than in the other years and remained at the high level for a long period. This phenomenon did not occur in the dry plot, which had a more regular variability within each of the years. Furthermore, the variability range between two measurements of soil water storage in the dry plot was smaller and did not show the high variability from year to year that was noted for the moist plot.

Carbon sequestration by trees was greatly different in different moisture plots, in response to different environmental conditions. According to data published by Berggren et al. (2004), average estimated carbon pool in tree biomass in the dry plots was $2614 \mathrm{~g} \mathrm{C} \mathrm{m}^{-2}$ in 2001 . However, that value was $4702 \mathrm{~g} \mathrm{C} \mathrm{m}^{-2}$ for the moist plots. In addition, average measured annual accumulation of carbon in tree biomass was $184 \mathrm{~g} \mathrm{C} \mathrm{m}^{-2} \mathrm{yr}^{-1}$ in the dry plots and $220 \mathrm{~g} \mathrm{C} \mathrm{m}^{-2} \mathrm{yr}^{-1}$ in the moist plots. For the understory layer, the average carbon pool was $218 \pm 115 \mathrm{~g} \mathrm{C} \mathrm{m}^{-2}$ in 2001 in the dry plots and $126 \pm 76 \mathrm{~g} \mathrm{C} \mathrm{m}^{-2}$ in 2001 in the moist plots.

\subsection{Air and soil temperature conditions}

According to findings from previous studies under similar climate conditions (Wu et al., 2011, 2012), the soil temperature acclimation function on photosynthesis and transpiration could not be replaced by a corresponding air temperature function except for warm years with very small delays between $T_{\mathrm{a}}$ and $T_{\mathrm{s}}$. Hence, spring delay patterns between cumulative air and soil temperatures were found for Knottåsen during 2001-2003 (Fig. 3). The spatial heterogeneity of $T_{\mathrm{s}}$ was reflected by the warmest $T_{\mathrm{S}}$ measurement for the dry plot and the coldest $T_{\mathrm{s}}$ measurement for the moist plot.

Cumulative $T_{\mathrm{a}}$ from April-June in 2001 was similar to that in 2003, but lower than that in 2002 (Fig. 3). Moreover, the timing of $T_{\mathrm{s}}$ warming in the moist plot was more delayed (about two weeks) than in the dry plot. This was partly because soil frost in the moist plot may have been 

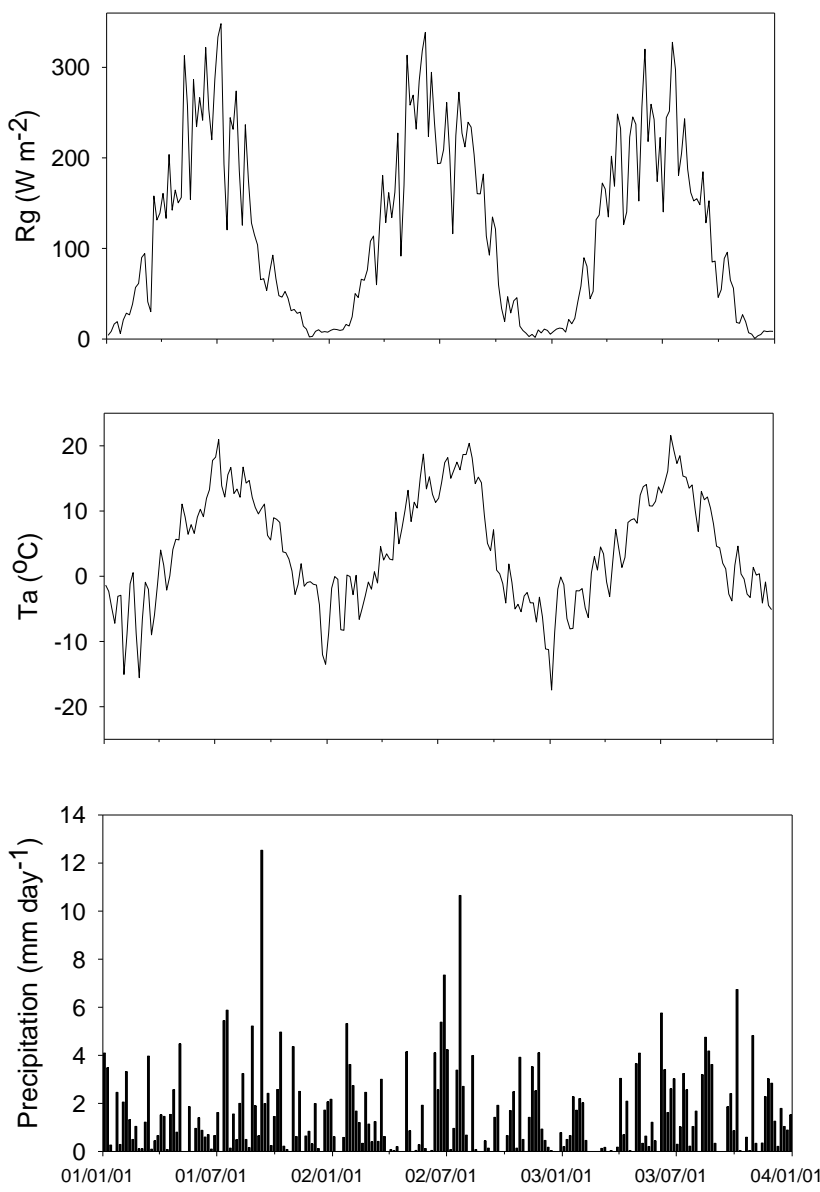

Fig. 1. Observed global radiation $\left(R_{\mathrm{g}}\right)$ (upper), air temperature $\left(T_{\mathrm{a}}\right)$ (center) and precipitation (lower) during 2001-2003. All values are 5-day averages.

more pronounced than that in the dry plot (Fig. 2a and b). Observed cumulative $T_{\mathrm{s}}$ from April-June in the dry plot was generally $80-100 \%$ higher than that in the moist plot in all three years. In the dry plot, a small delay between $T_{\mathrm{a}}$ and $T_{\mathrm{S}}$ warming occurred in 2001, while in $2002 T_{\mathrm{s}}$ was typically warmer than $T_{\mathrm{a}}$. However, in the moist plot, cumulative $T_{\mathrm{a}}$ was substantially higher than cumulative observed $T_{\mathrm{S}}$ in all three years.

The model showed an ability to simulate the various $T_{\mathrm{s}}$ measurements during all years since the measurements were within the simulated range (Fig. 3). This indicates that the model has flexibility to predict both cold and warm $T_{\mathrm{S}}$ using previous model assumptions and parameters (Wu et al., 2011, 2012). The mean value of simulated $T_{\mathrm{S}}$ (solid lines) based on behavioural models (when constrained by $\mathrm{C} 2$ ) was close to corresponding observed $T_{\mathrm{S}}$ (dotted lines) in the dry plot, whereas in the moist plot it was much higher than observed $T_{\mathrm{s}}$. The results also indicated that the flux data were better simulated by the warm and dry plot than by the corresponding cold and wet plot. Model assumptions and parameters related to soil heat and water processes might be
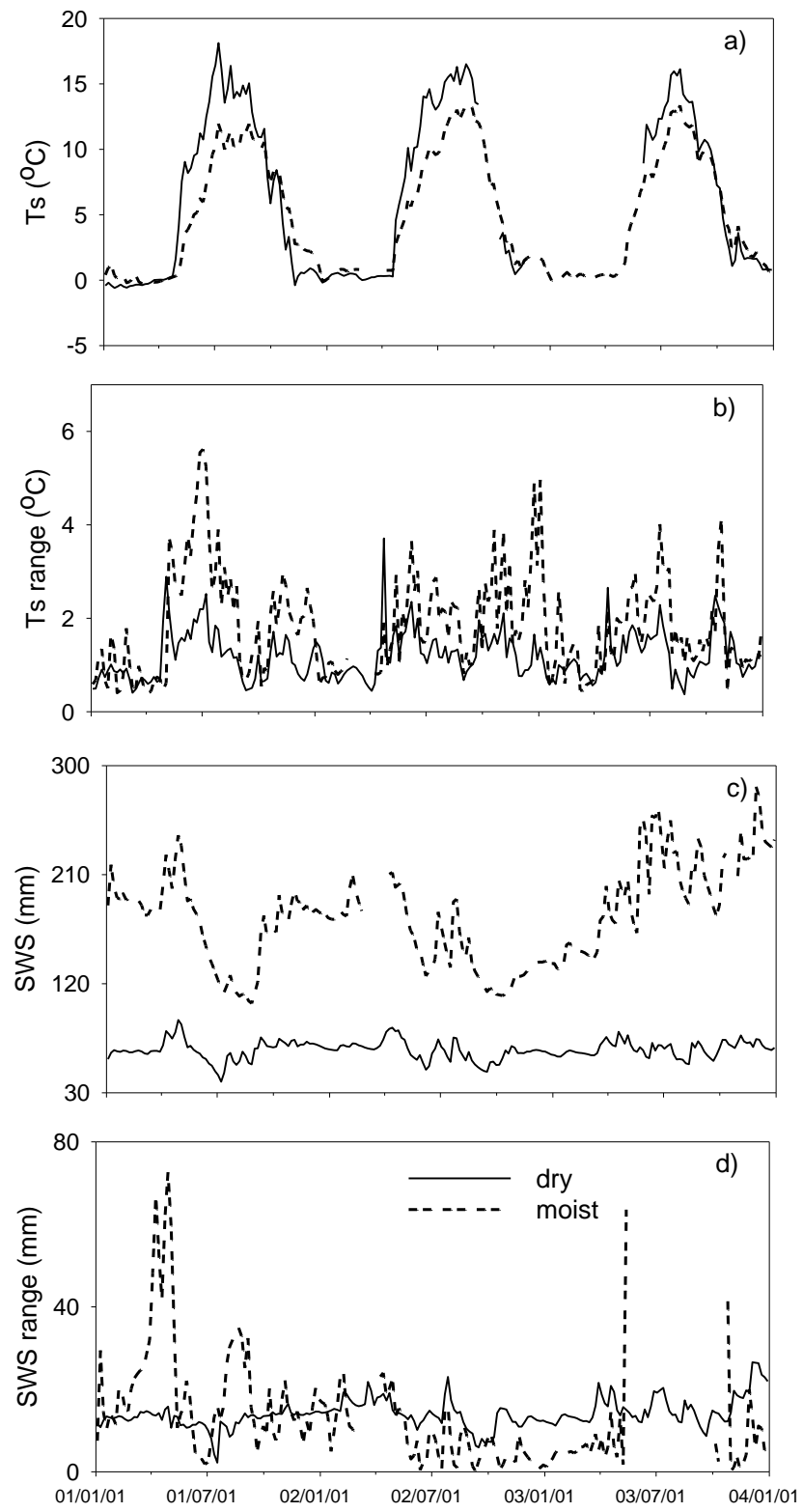

Fig. 2. (a) Observed soil temperature at $3 \mathrm{~cm}\left(T_{\mathrm{S}}\right)$. (b) The $T_{\mathrm{S}}$ variability range within the plot. (c) Observed soil water storage $(0$ $30 \mathrm{~cm})(\mathrm{SWS})$ and (d) the SWS variability range within the plot from dry and moist plots at Knottåsen during 2001-2003. All values are 5-day averages.

further adjusted to generate lower $T_{\mathrm{S}}$ under moist soil conditions. Unfortunately precise representation of moist and cold plots compared with dry and warm plots in the EC flux data was not possible, since carbon footprints around the tower could not exclude an impact of both conditions. However, the position of the tower suggests that the dry and warm conditions had more impacts on the results than the cold and moist conditions. 

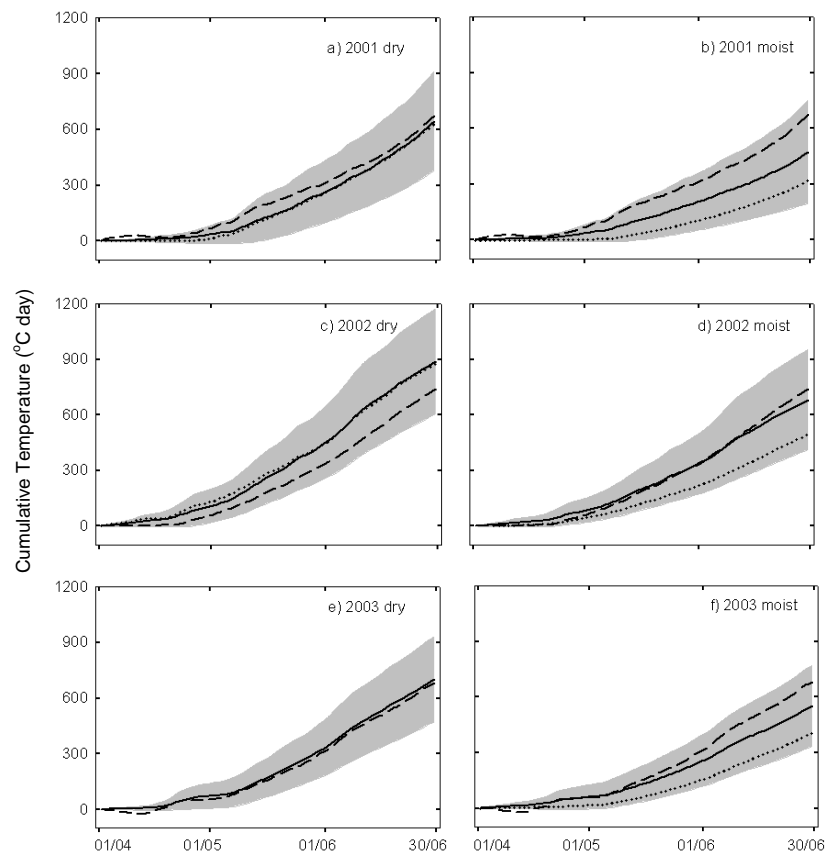

Fig. 3. Cumulative air and soil temperature from April to June in 2001, 2002 and 2003. The long dashed line is observed air temperature. The dotted line is observed soil temperature at $3 \mathrm{~cm}$ at the warmest position in the dry plot and at the coldest position in the moist plot, respectively. The grey area is the 5-95\% uncertainty band calculated from the 10000 posterior models accounting for dry and moist soil conditions. The grey area and solid line are the $5 \%$ and $95 \%$ uncertainty band and mean values of simulated soil temperature, respectively, based on the DryTs model assumption or based on the MoistTs model assumption when constrained by $\mathrm{C} 2$.

\subsection{Validity and seasonal patterns of simulated variables based on four model assumptions}

\subsubsection{Eddy covariance, soil temperature and soil moisture data}

In total, four different model assumptions were set up to account for dry and moist soil conditions at Knottåsen and to examine the effect of the soil temperature response function on photosynthesis. These were named DryTs, MoistTs, DryNoTs and MoistNoTs. Statistics on the performance of 11 variables in terms of $R^{2}$ and mean error (ME) were plotted for posterior 10000 simulations and behavioural models constrained by $\mathrm{C} 1$ and $\mathrm{C} 2$, respectively, based on DryTs, DryNoTs, MoistTs and MoistNoTs (Figs. 4 and 5).

Similar patterns for the performance and changes in performance were found for the four different model assumptions (Figs. 4 and 5). For eddy covariance (EC) variables, in the posterior distributions the dynamics were best described for $H$ and a systematic tendency to overestimate NEE and corresponding LE was obvious. Only $H$ was simulated with reasonably unbiased mean values.

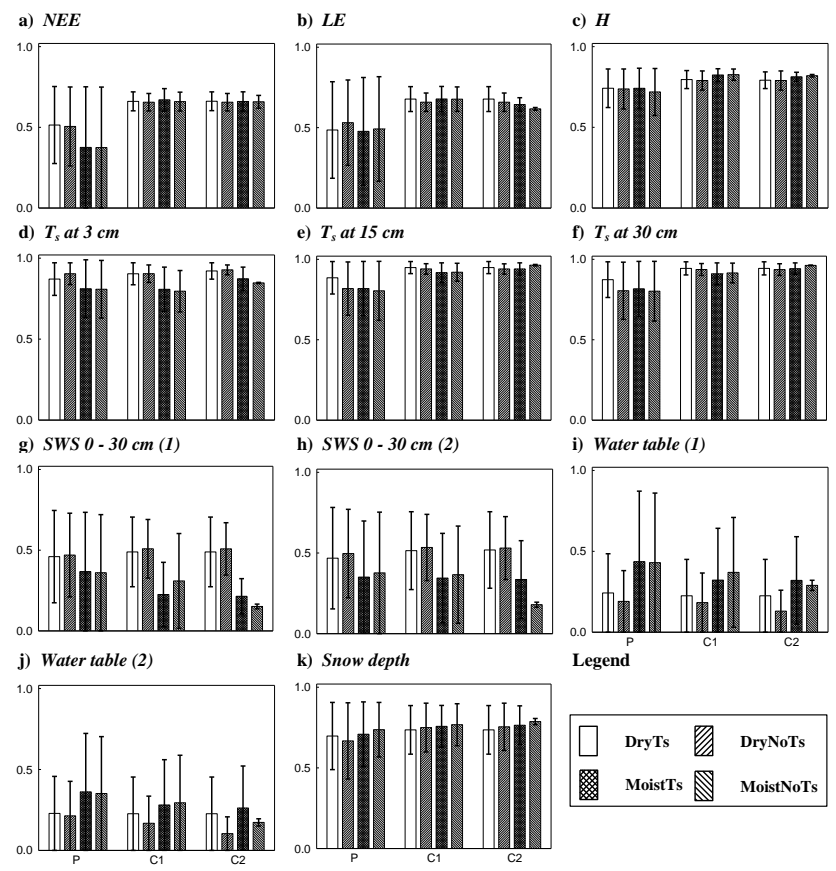

Fig. 4. Statistics of $R^{2}$ performance on 11 variables based on DryTs, DryNoTs, MoistTs and MoistNoTs model assumptions when not constrained (posterior $(\mathrm{P})$ ) or constrained by $\mathrm{C} 1$ or $\mathrm{C} 2$, respectively. All bars represent mean values and error bars represent min and max values.

Simulated $T_{\mathrm{S}}$ at three different depths agreed with measured $T_{\mathrm{S}}$ with respect to $R^{2}$ for both plots and ME for the dry plot (Figs. 4 and 5). However, the model showed a tendency to simulate soil in the moist plot in a similar way to that in the dry plot, suggesting it does not fully account for the direct effect of high moisture and high thickness of the organic layer. Both soil water storage and the water table were simulated with a high range of variability with respect to the dynamics and the corresponding mean values. However, the picture was more complicated for the water table. For the dry plot, too low water tables or too dry conditions were simulated, while for the moist plot there were no systematic problems, since both underestimations and overestimations occurred in all performance distributions. Maximum values of $R^{2}$ for the moisture variables were in the same order of magnitude as those for the EC fluxes. Mean values of soil water storage showed a tendency to be underestimated for both plots. Moreover, a wide range of ME was displayed among the posterior distribution, showing that simulations represented larger variability in moisture conditions than was observed. Snow depths were well simulated with relatively high values of $R^{2}$, normally above 0.5 and ME around zero.

In general, the results showed that we were able to represent high variability in soil conditions by the various model assumptions. The measured EC fluxes showed similar agreement with simulations also representing quite different moisture conditions and assumptions on soil temperature 


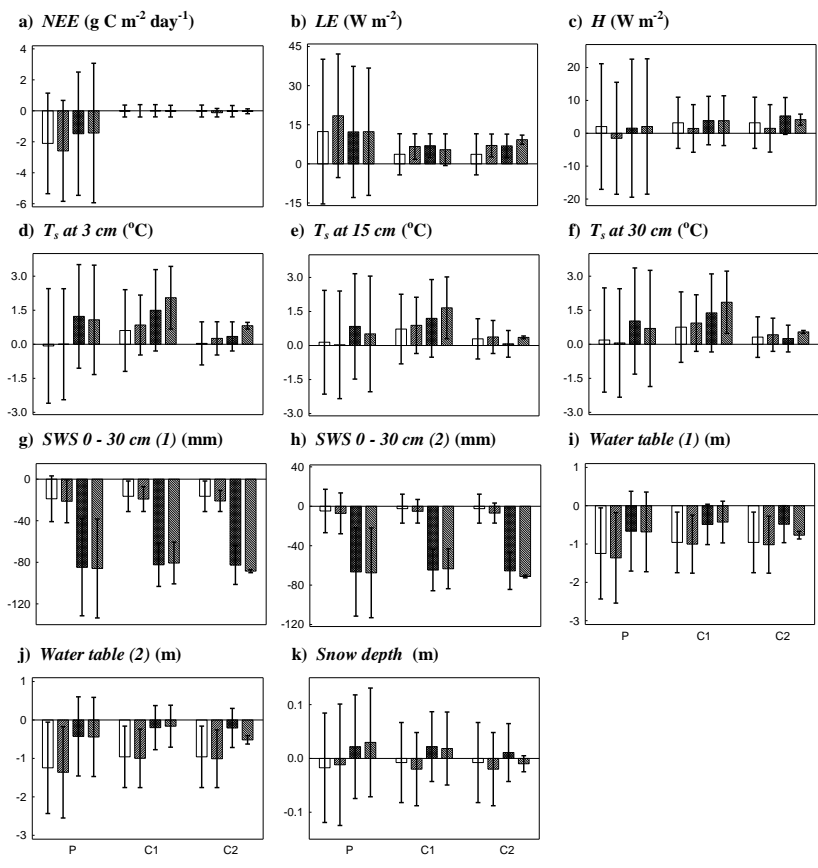

Fig. 5. Statistics on mean error (ME) performance on 11 variables based on DryTs, DryNoTs, MoistTs and MoistNoTs model assumptions when not constrained (posterior $(\mathrm{P})$ ) or constrained by $\mathrm{C} 1$ or $\mathrm{C} 2$, respectively. All bars represent mean values and error bars represent min and max values. For legend see Fig. 4.

impacts on the fluxes. This makes the EC fluxes less useful in understanding the importance of soil conditions for flux measurements, since EC fluxes represented and aggregated unknown combinations of fluxes from different environmental conditions.

\subsubsection{Differences between behavioural models}

When the simulations were constrained by EC fluxes only (C1), 278, 76, 296 and 135 behavioural models were obtained based on DryTs, DryNoTs, MoistTs and MoistNoTs, respectively. This indicated that model assumptions without the $T_{\mathrm{s}}$ response function (DryNoTs and MoistNoTs) showed less flexibility to generate behavioural models than model assumptions with the $T_{\mathrm{S}}$ response function (DryTs and MoistTs). Note that when constrained only on EC fluxes (C1), the performance of other variables was sometimes also improved, for example the soil temperature for the dry plot compared with the posterior distribution (Figs. 4 and 5). However, the same tendency was not shown for the moist conditions, where only marginal changes in the performance appeared after applying the same criteria. For some other variables such as soil moisture, only small changes occurred. In addition, simulated $T_{\mathrm{S}}$ was inclined to be overestimated, meaning that when simulated EC showed high agreement with observed EC, simulated $T_{\mathrm{S}}$ was probably warmer than observed.
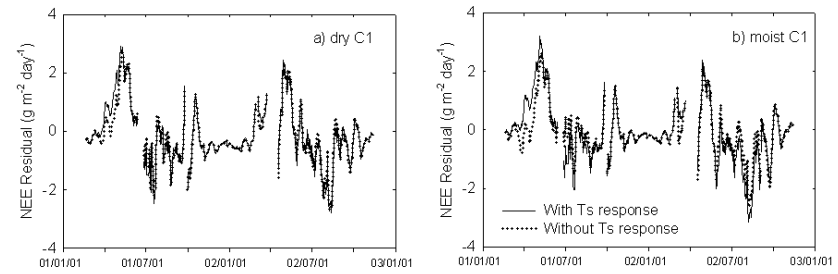

Fig. 6. Mean values of NEE residuals during 2001-2002 under dry and moist soil conditions, respectively, constrained by criteria $\mathrm{C} 1$. The solid line represents the mean NEE residuals based on DryTs or MoistTs, accounting for the effect of soil temperature responses on photosynthesis and transpiration. The dotted line represents the mean NEE residuals based on DryNoTs or MoistNoTs, without accounting for the effect of soil temperature responses on photosynthesis and transpiration. All values are 5-day averages.

In $\mathrm{C} 2$, when the model was constrained by EC fluxes and $T_{\mathrm{s}}$, the numbers of behavioural models $(204,35,48$ and 3 based on DryTs, DryNoTs, MoistTs and MoistNoTs, respectively) were substantially reduced compared with when constrained by EC fluxes only (C1). Surprisingly, the mean impacts of soil-based constraints on EC performance were minor for DryTs, DryNoTs and MoistTs. The performance on soil moisture measurements showed trade-off effects with less good values for the related performance indicators

In general the results indicated that reasonably good agreement could be obtained by many combinations of results where the single combination of soil and atmospheric conditions cannot be easily excluded. The smaller numbers of behavioural models when applying a simpler model without soil temperature impacts on fluxes indicate that such a soil temperature response existed in reality.

\subsubsection{Role of $T_{\mathrm{s}}$ in photosynthesis and transpiration}

In order to illustrate the importance of $T_{\mathrm{S}}$ effects on photosynthesis and transpiration, mean residuals of NEE based on DryNoTs or MoistNoTs were presented against those based on DryTs or MoistTs, when constrained by C1 (Fig. 6). Under both dry and moist soil conditions, only some differences between mean residuals of NEE were visible during spring 2001. Note that under dry soil conditions, positive mean residuals of NEE based on DryTs (with the $T_{\mathrm{s}}$ response function, solid lines) were slightly larger than for that based on DryNoTs (without the $T_{\mathrm{s}}$ response function, dotted lines) in Fig. 6a. This suggests that when a small delay between $T_{\mathrm{a}}$ and $T_{\mathrm{S}}$ occurred in spring, using only the air temperature response function might be good enough to predict acclimation of photosynthesis. However, under moist soil conditions, positive mean residuals of NEE based on MoistTs were shown in April 2001, while a similar magnitude of negative values based on MoistNoTs were shown (Fig. 6b). When constrained by $\mathrm{C} 1$ or $\mathrm{C} 2$, EC performance based on DryNoTs and MoistNoTs was generally similar to that based on DryTs 

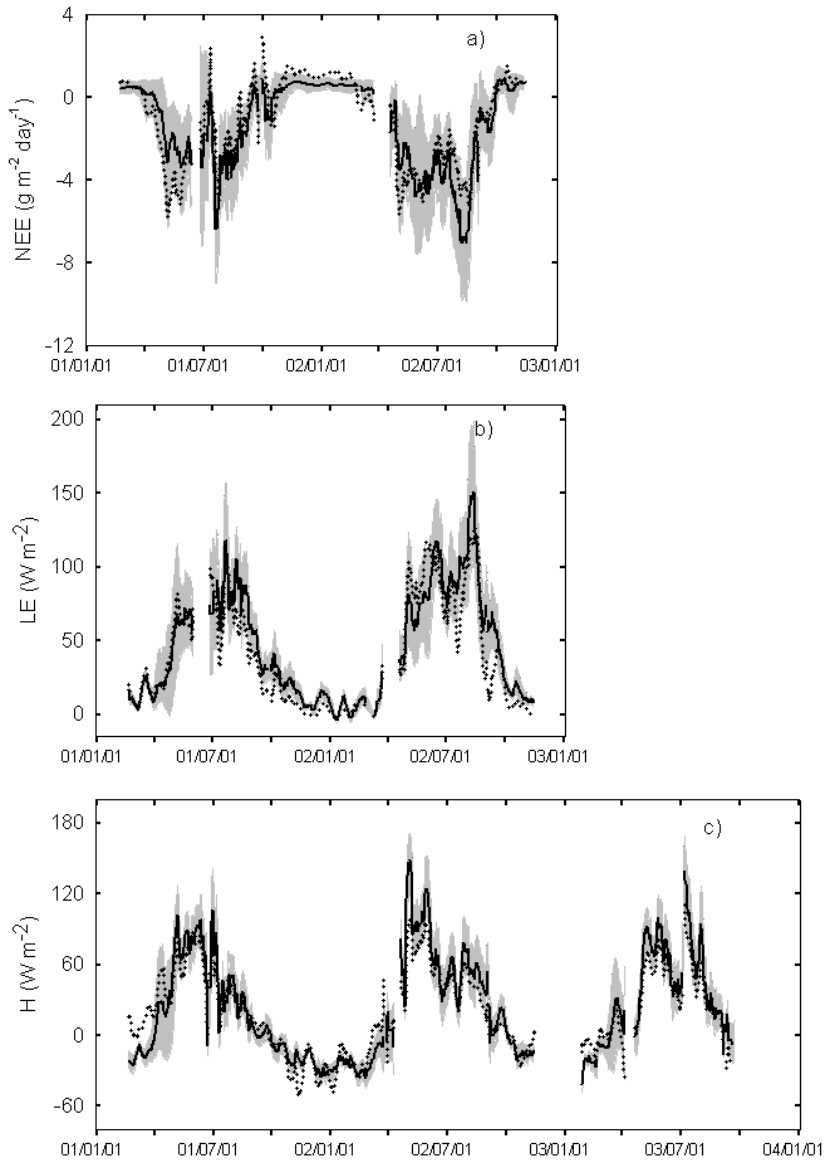

Fig. 7. Model performance on (a) NEE, (b) LE and (c) $H$ based on DryTs when constrained by criteria $\mathrm{C} 2$ against corresponding measurements. The dotted line shows measured data. The solid line and grey area are the mean values and the 5-95\% uncertainty band of simulated data based on 204 behavioural models. All values are 5-day averages.

and MoistTs, respectively (Figs. 4 and 5). Hence, it was difficult to identify the sensitivity of the response in EC fluxes to a large delay between $T_{\mathrm{a}}$ and $T_{\mathrm{S}}$ using the current approaches.

\subsubsection{Seasonal patterns of EC fluxes under dry or moist soil conditions}

Model performance on EC flux data based on DryTs and MoistTs constrained by $\mathrm{C} 2$ was similar in general. Thus, only performance based on DryTs is presented to demonstrate seasonal dynamics (Fig. 7). In addition, when constrained by $\mathrm{C} 2$, simulated $T_{\mathrm{S}}$ was closer to observed $T_{\mathrm{S}}$ than when constrained by $\mathrm{C} 1$.

Observed fluxes of NEE, LE and $H$ (dotted lines) during 2001-2002 (and 2003 for $H$ ) were mostly located within simulated 5-95\% uncertainty bands (grey areas) under dry (Fig. 7) and moist (not shown) soil conditions, meaning that seasonal courses of EC could be described by current behavioural models in general. Simulated $H$ (solid lines) in particular showed good agreement with measured $H$, with narrow uncertainty bands compared with NEE and LE. On the other hand, simulated NEE was systematically delayed compared with observed NEE in spring 2001, but this was not apparent in 2002. Observed LE in both early July 2001 and 2002 was sharply reduced due to summer drought, which was also described by simulated LE. In early August 2002, observed NEE and LE rates recovered substantially due to favourable conditions in air and soil. Simulated NEE and LE rates showed the same trend, but with higher mean flux rates compared with the observed rates. However, the systematic overestimation of LE did not correspond to an expected systematic underestimation of $H$ during the same events. Instead, $H$ showed a small tendency to be overestimated by the model.

One major difference in performance between DryTs and MoistTs was the timing and recovery rate of simulated NEE. When based on DryTs, these were earlier and faster than those based on MoistTs (not shown). Another difference was that mean simulated NEE based on MoistTs simulated larger uptake (more negative NEE) than that based on DryTs during summer periods in 2001 and 2002. These findings suggest that firstly, the recovery processes of photosynthesis and transpiration in forests under moist conditions were slower than those under dry conditions during spring, because of smaller snow depths and more pronounced frost events in moist soil than in dry soil. Secondly, the rates of photosynthesis and transpiration were considerably higher in the moist plots than in the dry plots during summer, as reflected by the differences in biomass measurements (Berggren Kleja et al., 2008; Svensson et al., 2008). Obviously the slow start in the spring had to be compensated for a longer period with high flux rates in the summer to explain the differences in biomass between moist and dry plots.

\subsection{Parameters obtained}

We tried to clarify differences in obtained parameter values obtained based on different model assumptions. Thus, statistics on influential parameters regarding mean value and the corresponding min-max range constrained by $\mathrm{C} 1$ and $\mathrm{C} 2$ are presented based on DryTs, DryNoTs, MoistTs and MoistNoTs (Fig. 8). In general, when constrained by $\mathrm{C} 1$ or $\mathrm{C} 2$, all calibrated parameter ranges and corresponding mean values were changed compared with corresponding prior values (Table 2). Furthermore, systematic patterns of parameters related to photosynthesis processes (Eq. 1-5 in Table 1) were revealed when comparing mean values of parameters under dry conditions with those under moist conditions. For instance, mean values of RadEfficiency(1)/(2) and $P \max (1) /(2)$ under dry conditions (Fig. 8) were lower than the corresponding parameter values under moist conditions, which could partly explain the lower NEE rates under dry conditions than under moist conditions. Differences in parameters related to the air temperature response function 


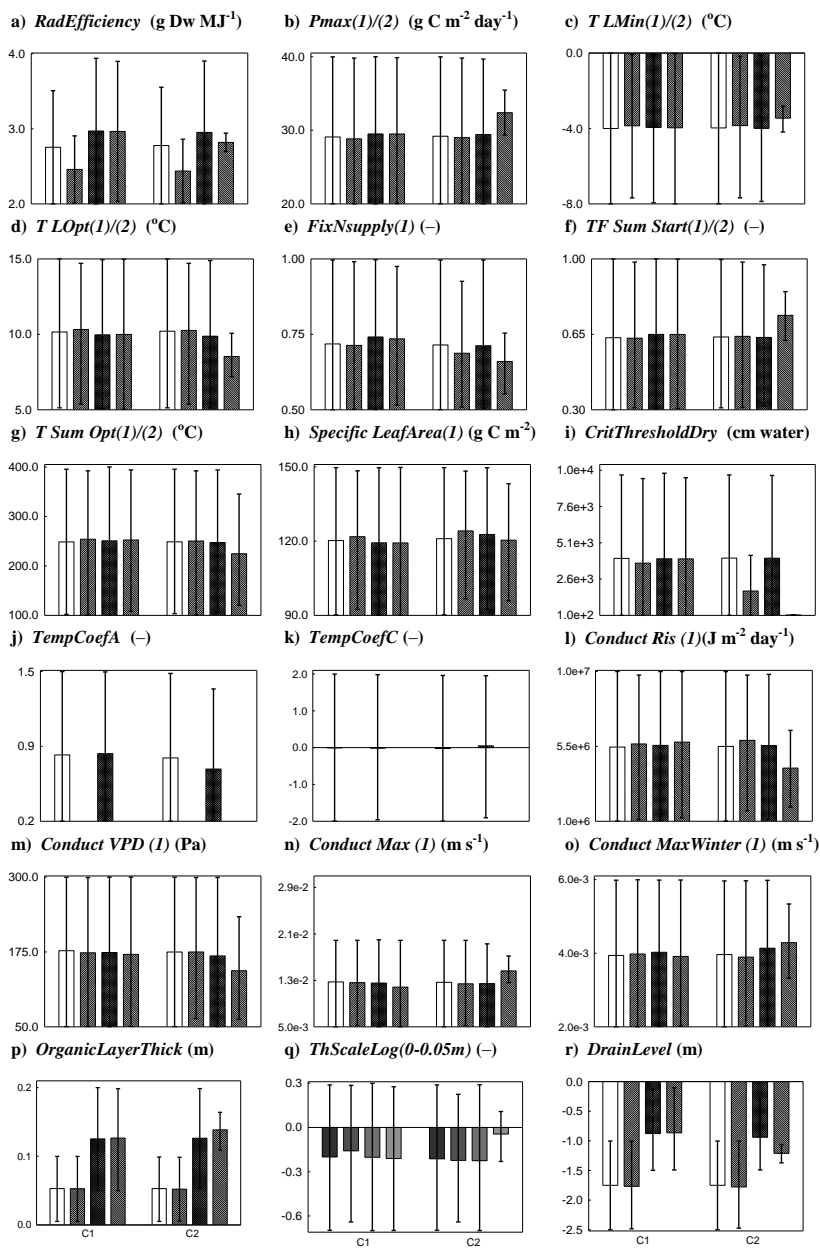

Fig. 8. Influential parameter performance based on DryTs, DryNoTs, MoistTs and MoistNoTs model assumptions when constrained by $\mathrm{C} 1$ or $\mathrm{C} 2$, respectively. All bars represent mean values and error bars represent min and max values. For legend see Fig. 4.

(T LMin(1)/(2), T LOpt(1)/(2), TF Sum Start(1)/(2) and T Sum $\operatorname{Opt}(1) /(2))$ suggest relatively less inhibition due to low air temperature under dry conditions than under moist conditions. It was interesting to note that nitrogen responses under moist conditions were normally higher than under dry conditions, implied by a scaling factor, FixN supply(1)/(2). When constrained by $\mathrm{C} 1$, mean values of Conduct Ris(1), Conduct VPD(1) and Conduct Max(1) based on DryNoTs or MoistNoTs were rather different to those based on DryTs or MoistTs, which indicates different influences depending on whether the soil temperature response function on transpiration is accounted for or not.

\subsection{Environmental factors regulating photosynthesis and transpiration}

The seasonality of effects of soil temperature and soil moisture response functions on photosynthesis and transpiration
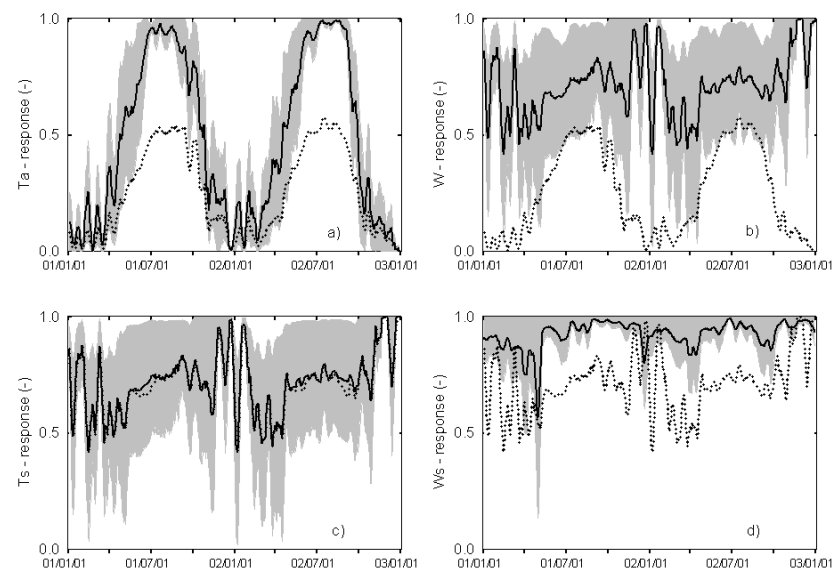

Fig. 9. Seasonal patterns of the effects of simulated daily response functions on photosynthesis processes ( $\mathbf{a}$ and $\mathbf{b}$ ) and on transpiration processes (c and d) during 2001-2002 for dry soil conditions. The different responses originate from air temperature (a), transpiration/water uptake by roots (b), soil temperature (c) and soil moisture (d). The grey area is the min-max response band based on 204 behavioural models using the DryTs model assumption when constrained by C2. The black solid line represents the mean of 204 behavioural individual responses, and the dotted line represents the multiplicative total response (including nitrogen for photosynthesis; (a) and (b)). All values are 5-day averages.

under dry soil conditions was similar to that under moist soil conditions, but the response ranges were generally different. This demonstrated that the model explained different environmental conditions using the same parameter values similar as a previous study by Wu et al. (2012). In that case a long time series of $12 \mathrm{yr}$ was used that created a high variability in contrast to the shorter period, with high spatial variability in soil conditions in this study. Effects of environmental factor response functions based on the DryTs model assumption when constrained by criteria $\mathrm{C} 2$ are only presented in Fig. 9. Clearly, air temperature was the major factor regulating photosynthesis in early spring and late autumn (Fig. 9a). The inhibition of photosynthesis and transpiration due to limitations from water uptake by roots was pronounced during late spring to late summer in 2001 and 2002 (Fig. 9b). In addition, the water response function effect on photosynthesis and transpiration originated mostly from the effect of soil temperature on water uptake (Fig. 9c). A systematic increase in the transpiration efficiency from spring to summer was present in both years.

Basically, photosynthesis and transpiration responses to different soil temperature and moisture conditions showed many similarities. While soil temperature was the major limiting factor on transpiration, soil moisture also played an important role in regulating photosynthesis and transpiration, especially under moist soil conditions. It is important to point out that seasonal patterns and abilities of carbon 
sequestration were expected to be different depending on the spatial variability of soil conditions.

\section{General discussion}

\subsection{Model performance and parameter uncertainties}

Because the EC data for Knottåsen used in this study were available for less than three years, the ability of the model to predict acclimation of photosynthesis in spring was only examined in 2001. In this period, a systematic delay in simulated NEE was obtained and compared with measured NEE based on DryTs and MoistTs. However, such a delay was not apparent for the LE data. This indicates that the seasonal response to transpiration was well described, but not the corresponding response for NEE. The similarity between LE and NEE found in the Scots pine study (Wu et al., 2012) was not equally clear for the present study, which makes interpreting the general difference between the two studies very uncertain. A systematic overestimation of both LE and $H$ suggests a likely problem in measurements at both sites and a certain systematic correction should be added for both the present study and the previous study of Scots pine at Hyytiälä (Wu et al., 2011).

\subsection{Measurement characteristics and impacts on model performance}

EC flux responses to dry and moist soil conditions were modelled and the unique results emphasised the impacts of $T_{\mathrm{s}}$ and moisture heterogeneity on modelling photosynthesis and transpiration. Total ecosystem biomass was reasonably simulated, with the mean value close to estimated biomass for the dry and moist plots (Berggren Kleja et al., 2008). Influential parameter values such as RadEfficiency(1)/(2) and $P \max (1) /(2)$ were generally different under dry and moist conditions, indicating that soil conditions are strongly linked to the overall behaviour of the ecosystem. Hence, a proper description of vegetation and soil conditions is important in understanding the holistic ecosystem processes and the relationship between soil temperature and air temperature.

\section{Conclusions}

In general, the seasonality of NEE, LE and $H$ of a Norway spruce stand in Sweden during the study period was modelled successfully using previous model assumptions and parameters from a study on Scots pine in Finland. Simulations of the different soil conditions showed a series of possible explanations for the measured EC fluxes, but could only be constrained by the corresponding soil measurements. Different ecosystem responses to dry and moist soil conditions were presented but not confirmed by the EC fluxes, since they could not be differentiated to represent various footprints.
The major conclusions from testing model applicability for prediction of photosynthesis and transpiration in response to cold climate were:

a. Prior parameter ranges were able to represent the spatial differences in soil temperature and soil moisture conditions at the site and behavioural models were found for both dry and moist soil plots.

b. The empirical soil temperature response function was useful to regulate simulated transpiration, sensible heat flux, and photosynthesis and generated much higher numbers of behavioural models than corresponding simulations based only on the air temperature response function.

c. Large uncertainty bands were obtained for most of the regulating parameters since many equifinalities existed when an eddy-covariance flux site had high variability in soil conditions.

Acknowledgements. This paper is the result of a joint project between China Scholarship Council (CSC) and School of Architecture and Built Environment (ABE) at KTH. The authors thank Anders Lindroth, who provided the measured data. The authors also acknowledge Xiaoming Zhang, who supported the linguistic revision and the editorial help.

Edited by: K. Bishop

\section{References}

Berggren, D., Bergkvist, B., Johansson, M.-B., Langvall, O., Majdi, H., Melkerud, P.-A., Nilsson, Å., Weslien, P., and Olsson, M.: A Description of LUSTRAs Common Field Sites. Reports in Forest Ecology and Forest Soils, No 87, Swedish University of Agricultural Sciences, ISSN 0348-3398, 2004.

Berggren Kleja, D., Svensson, M., Majdi, H., Jansson, P.-E., Langvall, O., Bergkvist, B., Johansson, M.-B., Weslien, P., Truusb, L., Lindroth, A., and Ågren, G. I.: Pools and fluxes of carbon in three Norway spruce ecosystems along a climatic gradient in Sweden, Biogeochem., 89, 7-25, 2008.

Bergh, J. and Linder, S.: Effects of soil warming during spring on photosynthetic recovery in boreal Norway spruce stands, Global Change Biol., 5, 245-253, 1999.

Beven, K. J.: A Manifesto for the equifinality thesis, J. Hydrol., 320, 18-36, 2006.

Boisvenue, C. and Running, S. W.: Impacts of climate change on natural forest productivity - evidence since the middle of the 20th century, Global Change Biol., 12, 1-21, 2006.

Brooks, R. H. and Corey, A. T.: Hydrological Properties of Porous Media, Colorado State University, USA, 1964.

Ensiminger, I., Schimdt, L., and Lloyd, J.: Soil temperature and intermittent frost modulate the rate of recovery of photosynthesis in Scots pine under simulated spring conditions, New Phytol., 177, 428-442, 2008. 
Jansson, P.-E. and Karlberg, L.: Theory and practice of coupled heat and mass transfer model for soil-plant-atmosphere system (in Chinese), ISBN: 978-7-03-025728-4, Science Press, China, 1-309, 2009.

Jansson, P.-E. and Karlberg, L.: Coupled heat and mass transfer model for soil-plant-atmosphere systems. Royal Institute of Technology, Stockholm, 484 pp., available at: http://www.lwr. kth.se/Vara\%20Datorprogram/CoupModel/coupmanual.pdf, 2010.

Jansson, P.-E. and Moon, D. S.: A coupled model of water, heat and mass transfer using object-orientation to improve flexibility and functionality, Environ. Modell. Softw., 16, 37-46, 2001.

Jansson, P.-E., Svensson, M., Berggren, Kleja, D., and Gustafsson, D.: Simulated climate change impacts on fluxes of carbon in Norway spruce ecosystems along a climatic transect in Sweden, Biogeochem., 89, 81-94, 2008.

Kolari, P., Lappalainen, H. K., Hänninen, H., and Hari, P.: Relationship between temperature and the seasonal course of photosynthesis in Scots pine at northern timberline and southern boreal zone, Tellus, 59B, 542-552, 2007.

Lindroth, A., Klemedtsson, L., Grelle, A., Weslien, P., and Langvall, O.: Measurement of net ecosystem exchange, productivity and respiration in three spruce forests in Sweden shows unexpectedly large soil carbon losses, Biogeochem., 89, 43-60, 2008.

Mäkelä, A., Hari, P., Berninger, F., Hänninen, H., Nikinmaa, E., 2004. Acclimation of photosynthesis capacity in Scots pine to the annual cycle temperature. Tree Physiol. 24, 369-378, 2004.

Mellander, P.-E., Stähli, M., Gustafsson, D., and Bishop, K.: Modelling the effect of low soil temperatures on transpiration by Scots pine, Hydrol. Process., 20, 1929-1944, 2006.
Mellander, P.-E., Bergh, J., Lundmark, T., and Bishop, K.: Recovery of photosynthesis capacity in Scots pine: a model analysis of forest plots with contrasting soil temperature, Eur. J. Forest Res., 127, 71-79, 2008.

Schröter, D., Cramer, W., Leemans, R., Prentice, I. C., Araújo, M. B., Arnell, N. W., Bondeau, A., Bugmann, H., Carter, T. R., Gracia, C. A., de la Vega-Leinert, A. C., Erhard, M., Ewert, F., Glendining, M., House, J. I., Kankaanpää, S., Klein, R. J., Lavorel, S., Lindner, M., Metzger, M. J., Meyer, J., Mitchell, T. D., Reginster, I., Rounsevell, M., Sabaté, S., Sitch, S., Smith, B., Smith, J., Smith, P., Sykes, M. T., Thonicke, K., Thuiller, W., Tuck, G., Zaehle, S., and Zierl, B.: Ecosystem service supply and vulnerability to global change in Europe, Science, 310, 1333-1337, 2005.

Suni, T., Berninger, F., Vesala, T., Markkanen, T., Hari, P., Mäkelä, A., Ilvesniemi, H., Hänninen, H., Nikinmaa, E., Huttula, T., Laurila, T., Aurela, M., Grelle, A., Lindroth, A., Arneth, A., Shibistova, O., and Lloyd, J.: Air temperature triggers the recovery of evergreen boreal forest photosynthesis in spring, Global Change Biol., 9, 1410-1426, 2003.

Svensson, M., Jansson, P.-E., Gustafsson, D., Berggren, Kleja, D., Langvall, O., and Lindroth, A.: Bayesian calibration of a model describing carbon, water and heat fluxes for a Swedish boreal forest stand, Ecol. Modell., 213, 331-344, 2008.

Wu, S. H., Jansson, P.-E., and Kolari, P.: Modeling seasonal course of carbon fluxes and evapotranspiration in response to low temperature and moisture in a boreal Scots pine ecosystem, Ecol. Modell., 222, 3103-3119, 2011.

Wu, S. H., Jansson, P.-E., and Kolari, P.: The role of air and soil temperature in the seasonality of photosynthesis and transpiration in a boreal Scots pine ecosystem, Agr. Forest Meteorol., 156, 85$103,2012$. 